\title{
Influencia de la ESCALA de decisión e intervención en el proceso de mejora y producción social del hábitat (La gestión y el control social de la ciudad)
}

\author{
Influence of the scale of decision and intervention in the process of \\ improvement and social production of habitat (Management and \\ social control of the city)
}

\section{Pedro Lorenzo Gálligo*}

Fecha de recepción: 11-06-2014 - Fecha de aceptación: 27-01-2015

Hábitat y Sociedad (ISSN 2173-125X), n. ${ }^{\circ} 8$, noviembre de 2015, pp. 43-72.

\section{Summary}

Housing constitutes an essential part of the human habitat of a city.

The fact of accommodating or being accommodated can produce overflows or can suffer the presence of overflows (social, economic, physical) produced by others. Populations, in order to be housed, can either settle in the living space provided by others (for the market) or they can create their own home, their own town (to inhabit). In order to subsequently improve their habitat or to prevent habitat degradation or destruction (usually by economic pressure), they try to individually or collectively influence the decisions and management of the continuous process of evolution and transformation of their neighbourhood, city, country...

This process can be affected by various factors (social, economic, cultural, physical, and environmental), agents (people, politicians, technicians, producers, and capital), and mechanisms (theories, policies, programs, projects, and techniques).

A decisive factor in the outcome of the process is the scale on which this occurs (individual home, collective housing, neighbourhood, city, country, geo-economic area, global).

Seven examples of the relationship scale-factorsagents-mechanisms of improvement, creation of habitat are analysed in Spain.

The conclusion is: a) Not on all scales did this relationship perform equally; b) Achieving the habitat on the proper scale can influence and transform decisions regarding habitat on other scales.

\section{Key words}

Habitat, Production and Social Management of Habitat, Self-Management, Co-Management, Scale

\section{Resumen}

El alojamiento es una parte esencial del hábitat humano, de la ciudad.

El hecho de alojarse, o alojar puede ser causa de desbordes o sufrir la presencia de desbordes (sociales, económicos, físicos) producidos por otros.

Las poblaciones, para alojarse o se instalan en el espacio habitable producido por otros (para el mercado) o producen su propia vivienda, su propia ciudad (para habitar), después, para mejorar su hábitat o impedir su degradación o destrucción (generalmente por la presión económica) intentan influir, individual o colectivamente, en las decisiones y gestión del proceso continuo de evolución y transformación de su hábitat, barrio, ciudad, país...

En este proceso inciden diversos factores (sociales, económicos, culturales, físicos y medioambientales), agentes (población, políticos, técnicos, productores y capital) y mecanismos (teorías, políticas, programas, proyectos y técnicas).

Un factor fundamental, determinante en el resultado del proceso, es la escala en la que este se produce (vivienda propia, vivienda colectiva, barrio, ciudad, país, zona geoeconómica, global).

Se analizan 7 ejemplos de la relación escala-factoresagentes-mecanismos de la mejora, producción del hábitat, en España.

La conclusión es: a) No a todas las escalas se actúa igual; b) Lograr el hábitat a la propia escala permite incidir, transformar las decisiones a otras escalas.

\section{Pallabras clave}

Desbordes urbanos, Emergencia, Periferia, Investigación; Sostenibilidad, Hábitat

\footnotetext{
* Doctor, Arquitecto. PLEST Estudio de Arquitectura plest@coac.es. Miembro de: Grupo de trabajo AWB. Actions Without Borders, de UIA. Union Internacional de Arquitectos. Red CYTED. Des-Bordes Urbanos.
} 
Generalmente hablamos de cuestiones comunales y yo, más perspicaz en este aspecto a causa de mi aislamiento, suelo asombrarme de la riqueza de espiritu que necesita un perro común, aun en circunstancias no excesivamente desfavorables, para ir por la vida y protegerse de los peligros corrientes. Es la ciencia de las reglas, pero no resulta fácil comprenderla ni aun en sus planteamientos más elementales, y solo una vez comprendida viene la verdadera dificultad: aplicarla a las circunstancias ordinarias.

KAFKA, Franz. Investigaciones de un perro. La Muralla China, 2001, p. 170.

\section{Introducción}

El hábitat existente es el resultado del hecho de alojarse, de conseguir un espacio habitable en un lugar para vivir y es, a su vez, el resultado de la propuesta de alojamiento, de alojar, por parte de agentes (políticos, técnicos, productores) que no son los que habitan en el espacio propuesto, e intervienen con diversos objetivos que pueden estar en coincidencia, ser ajenos o contrarios a los de los que se alojan (poder, prestigio, beneficio económico...).

La realidad del hábitat y en concreto de la ciudad existente, en la que se concentran muy especialmente las características del hábitat actual, es el resultado de la actuación de los poderes, capacidades, deseos e intenciones de los agentes en presencia, con el resultado de múltiples maneras de proponer o mejorar el espacio habitable, entre las que, para aclarar y profundizar en los hechos, podemos distinguir dos: aquella que busca la satisfacción de la necesidad y la posibilidad de vivir (ciudad para vivir), y aquella que busca el beneficio propio (económico fundamentalmente, pero también político o de prestigio) incluso aunque el resultado no sea una ciudad para habitar (ciudad para vender).

Cuando se analiza el concepto de desborde urbano surge como primera referencia la transformación de la dimensión de la ciudad, la evolución de las periferias donde la posesión del suelo es un gran campo de acción de las dos maneras de ocupar el espacio: conseguirlo para vivir o edificarlo para vender. Este no es en absoluto el único lugar donde se producen los desbordes (no solo físicos, sino sociales, económicos y culturales) en la ciudad. La ciudad ya edificada (el centro consolidado) o las áreas rurales donde la ciudad se asienta, son objetivo de la lucha por el espacio, por el mantenimiento de derechos, por la defensa ante la exclusión o erradicación, por la conservación del espacio rural y agrícola necesario.

Estos procesos de producción o mejora del hábitat se dan en unas condiciones concretas sociales, económicas y culturales en un lugar concreto y en unas condiciones medioambientales, es decir, responden a necesidades y posibilidades generales que el hombre tiene para habitar pero, a su vez, son condicionados por las características específicas del lugar donde se desarrollan, de la identidad del lugar.

La ciudad es un lugar donde estos procesos se desarrollan, pero no es el único. Desde las macroescalas (derecho universal a la vivienda o a la ciudad), las áreas económicas o culturales (Unión Europea, Mercosur...), los Estados, hasta las pequeñas escalas (barrios, pueblos y zonas 
rurales...), así como las microescalas (asentamientos, condominios, calles, edificios...) se influye en las dos realidades: búsqueda de la necesidad o posibilidad de vivir o búsqueda de otras intenciones económicas, políticas y técnicas, condicionando los distintos procesos de evolución, adaptación o transformación del hábitat.

Si el objetivo es alojarse y alojar para satisfacer la necesidad y posibilidad de vivir en un lugar, es útil analizar las variables, los conceptos, los factores, los agentes y los mecanismos que intervienen en los procesos, así como la influencia de la escala en la que se decide e interviene.

\section{Variables a analizar en los procesos de mejora y/o construcción del hábitat:}

\subsection{Los conceptos Alojarse/Alojar}

Para el habitante alojarse, conseguir un techo donde vivir o mejorar el propio alojamiento, precario o no, que ha construido o en el que ha conseguido instalarse, es una continua necesidad, preocupación o deseo, no la única, ni siquiera la prioritaria, como puede ser alimentarse, curarse, educarse o salir de una situación de riesgo, pero sí básica y estructural para sus condiciones de vida.

Alojar a las poblaciones es, por un lado, uno de los problemas prioritarios de la humanidad, el principal problema de la arquitectura, entretenida en la producción de objetos fotografiables de éxito, poder o "prestigio", básicamente económicos.

Alojarse o mejorar el alojamiento, para la mayoría de la población mundial, no es acceder a un bien existente, comprado en el mercado del hábitat (ciudad formal), sino recorrer un proceso de organización y gestión, económico (generalmente sin acceso al crédito) y técnico (con acompañamiento o sin acompañamiento), que puede suponer años (decenas de años) para conseguir una vivienda no precaria y una ciudad, un lugar, un barrio o un pueblo, no precarios.

Este proceso de alojarse, para la mayoría de la población a nivel mundial, es tan necesario como complejo, no es lineal ni plácido, sino turbulento, esforzado y, lo que es clave para el resultado observable, no solo no está apoyado o asistido, sino que está continuamente amenazado, condicionado o dificultado por continuos intereses de otros agentes en presencia, en los inicios (cómo llegar a asentarse en un lugar) o en el tiempo (cómo conseguir mantenerse en un lugar apetecido por intereses inmobiliarios, políticos o productivos o, simplemente, para conseguir que el lugar donde se habita no sea degradado o destruido por esos intereses).

Esta es una situación común en los barrios sociales y pequeños núcleos históricos de los barrios de las ciudades españolas, barrios en muchos casos realizados por el esfuerzo comunitario y contemplados como no deseados por los planes generales, en los que la propuesta suele ser su destrucción y la transformación de su modelo de vida por otro, generalmente favorable al negocio inmobiliario, ocasión que aprovechan los especuladores para destruir el barrio y transformarlo en un mercado. Es el caso, por ejemplo, del núcleo histórico del barrio de Vallcarca, en Barcelona, pero los ejemplos pueden ser muchos y en múltiples ciudades. 


\section{Calidad del hábitat. Acerca de la opinión de distintos agentes. Políticos y técnicos}

Es curioso contemplar el papel que ejercen ciertos actores ante el hecho de la mejora del hábitat, en concreto los políticos y los técnicos.

Los políticos consideran que los asentamientos humanos, el hábitat autogestionado, autodiseñado y el autoconstruido "avergüenzan" su prestigio, su ciudad o su país. No entienden o no quieren entender que las poblaciones han logrado resolver ellas solas su problema de hábitat y en lugar de apoyarlas para su mejora con elementos sencillos y económicos (legalización de suelo, hacerles objeto de crédito o auxiliarles técnicamente), proponen destruir su trabajo y esfuerzo, erradicándoles, excluyéndoles o desplazándoles.

Los técnicos, formados para la realización de la ciudad formal y, prioritariamente, para la aspiración a una arquitectura "artística", realizada para fotografiar y mirar, en lugar de para vivir, cuando no para vender o representar, una arquitectura en la que el cliente es quien la paga y no quien la vive, observan escandalizados la arquitectura autoconstruida como algo que hubiera necesitado de ellos (ellos que no la han considerado como objeto de su trabajo) y consideran que hay que destruirla, que debe desaparecer y que debe ser sustituida por otra propuesta suya (ellos que han abandonado a las poblaciones a las que no han reconocido como su verdadero cliente y han trabajado para los promotores).

\subsection{Factores que intervienen en el proceso}

En el proceso de producción y mejora del hábitat intervienen como factores básicos:

\subsubsection{Factores de la actividad humana}

Estos factores se pueden agrupar en:

- Factores sociales, que determinan las necesidades y posibilidades, las alternativas, capacidades y oportunidades de las poblaciones para el desarrollo de su propia vida, en distintos grados de libertad.

Entre estos factores están la capacidad de organización y gestión (cogestión y autogestión), la de participación en las decisiones colectivas y en la gestión pública (definición y aplicación de las propuestas políticas).

Estos factores sociales se desarrollan en un régimen de competencia y en una generalizada situación de dominio-dependencia-exclusión de los distintos grupos sociales en presencia.

- Factores económicos, que determinan el acceso a los bienes necesarios o posibles para el desarrollo de la propia vida (acceso al trabajo, a los alimentos, a la enseñanza, a la sanidad, al hábitat, al deporte, al ocio...) y su uso, en una situación que va desde el despilfarro y la abundancia hasta la carencia, la supervivencia y la indigencia.

Estos factores económicos se desarrollan en un régimen de desequilibrio, que tiene dos situaciones de gran influencia, reconocibles:

- El desequilibrio global, con los países desarrollados dominantes, que hace que $15 \%$ de la humanidad tenga el $75 \%$ de los bienes totales.

- El desequilibrio local, en el que el abanico económico refleja una concentración económica minoritaria más acentuada en los países más pobres y una continua separación y alejamiento 
de los sectores socioeconómicos en el conjunto de los países. En España, la separación entre quintiles, 20\% que más gana con respecto al $20 \%$ que menos gana, ha pasado con la actual crisis de 7-8 veces a 12-14 veces.

Estos factores económicos y su evolución, inciden directamente en la capacidad de acceso al hábitat propio, independientemente del sistema de tenencia (propiedad individual o colectiva, alquiler...).

- Factores culturales, que reflejan elementos clave para abordar la mejora y producción del hábitat: los modos de vida, las necesidades y las posibilidades de las poblaciones para el desarrollo de su vida.

Estos factores se desarrollan en una situación generalizada de identidad-exclusión, así como de homogenización-anulación cultural.

\section{FACTORES DE LA ACTIVIDAD HUMANA}
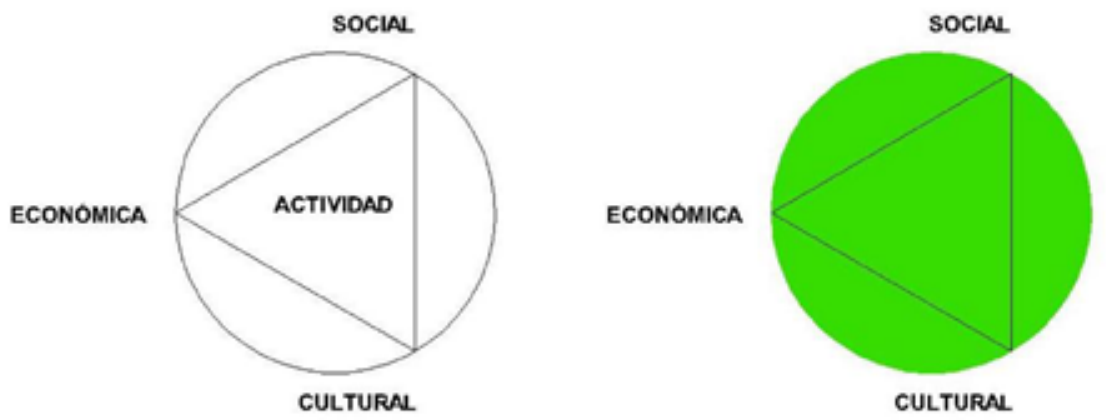

MAXIMA SATISFACCION

La figura 1 muestra los factores sociales, económicos y culturales, es decir, los factores no tangibles, y expresa distintas situaciones.

La máxima satisfacción indica una situación de capacidad de acceder a los factores por parte de un grupo social minoritario. La capacidad de acceder no indica el uso real de los factores.

La situación de carencia indica la incapacidad de acceder a un grado de satisfacción de los factores por parte de un grupo social determinado. Esta situación de carencia es mayoritaria a nivel mundial, con distintos grados de proporción según el nivel de desarrollo (dominio o dependencia) de los países.

\subsubsection{Factores del soporte físico en el que se desarrolla la vida de las poblaciones}

Estos factores se pueden agrupar en tres áreas:

- Factores del espacio habitado. En un sentido amplio, el espacio que se usa para habitar, desde la propia vivienda, sus espacios complementarios, la calle, el barrio o la ciudad, con sus edificios de equipamiento (enseñanza, sanidad, cultura, ocio, deporte), o el territorio donde se asienta la ciudad y el espacio rural.

Este espacio responde a distintas situaciones desde las de calidad y de abundancia hasta las de escasez, precariedad (degrada-

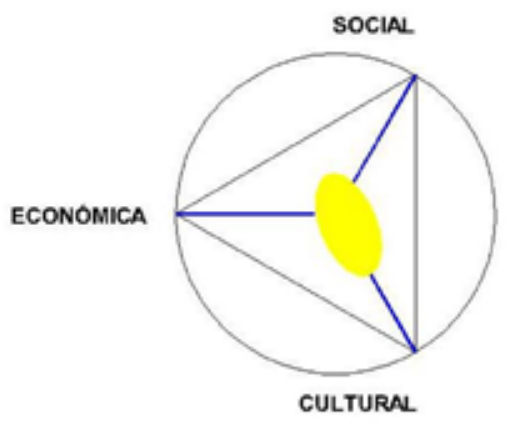

SITUACION DE CARENCIA

Figura 1. Factores de la actividad humana. Fuente: Elaboración propia. 
ción, falta de calidad de la edificación y situaciones de riesgo) o hacinamiento.

Características importantes del espacio habitado son el grado de tenencia segura y el grado de exclusión de su uso (espacio público y equipamientos).

- Servicios e infraestructuras del espacio, es decir, aquellas condiciones necesarias para el uso del espacio, desde la accesibilidad al lugar a la posibilidad de utilización de los servicios (agua, energía, saneamiento...).

- Factores medioambientales en los que el espacio físico se desarrolla (geográficos, climáticos...), en especial aquellos factores externos al espacio físico (ciudad, por ejemplo) de los que se depende (aire, agua, alimentos, productos) y aquellos que produce el espacio físico y envía a otros espacios o recicla (aire contaminado, desechos... etc.).

\section{FACTORES DEL SOPORTE FISICO}

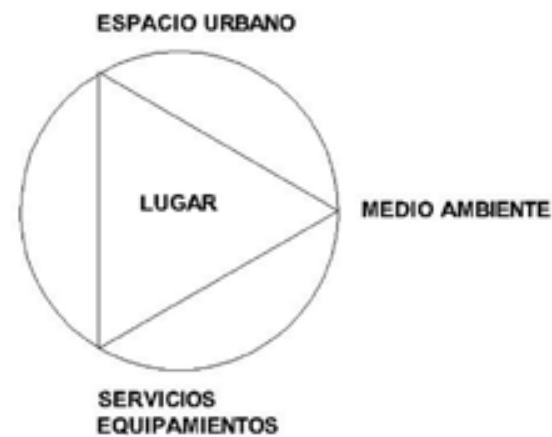

Figura 2. Factores del soporte físico. Fuente: Elaboración propia.
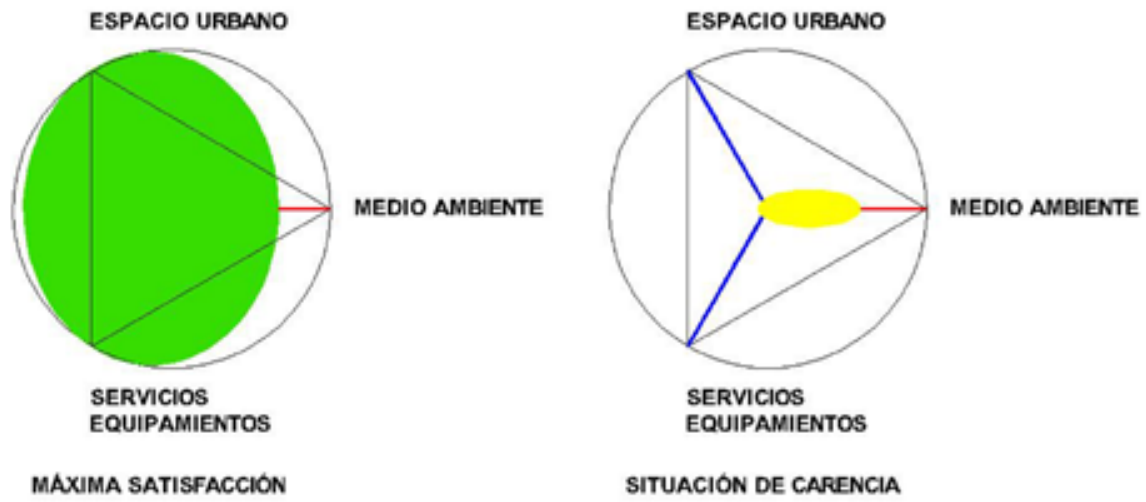

La figura 2 muestra los factores físicos y permite observar las distintas situaciones límite que se producen:

La máxima satisfacción indica una situación de abundancia de espacio, dotado con la máxima calidad de servicios y en una situación general (habitual en todos los países) de una cierta carencia medioambiental.

Una situación de precariedad (la situación de un asentamiento humano, o de un barrio o edificio degradado, mayoritaria en el mundo) indica escasez o carencia de espacio físico (tugurización), de espacio urbano, de equipamientos, de servicios y, posiblemente, un agravamiento a microescala de las condiciones medioambientales.

La figura 3 indica la simultaneidad de situaciones de abundancia (minoritarias) y escasez (mayoritarias), tanto en los factores de la actividad humana como en los factores del soporte físico. A nivel global la situación de escasez es mayor del $60 \%$, llegando al $80 \%$ en ciertas zonas o países. En España es del 20-30\%, aumentando en estos momentos como consecuencia de la crisis.

La suma de los factores de la actividad humana y de los factores físicos indica, por un lado, la situación de calidad de vida de las poblaciones y, por otro, la situación ecológica (relación de la población con su medio) y las condiciones de sostenibilidad (social, económica y medioambiental) o, con mayor precisión, la necesidad de un proceso de respuesta, de adaptación o transformación, para conseguir unas verdaderas condiciones de calidad de vida y sostenibilidad. 


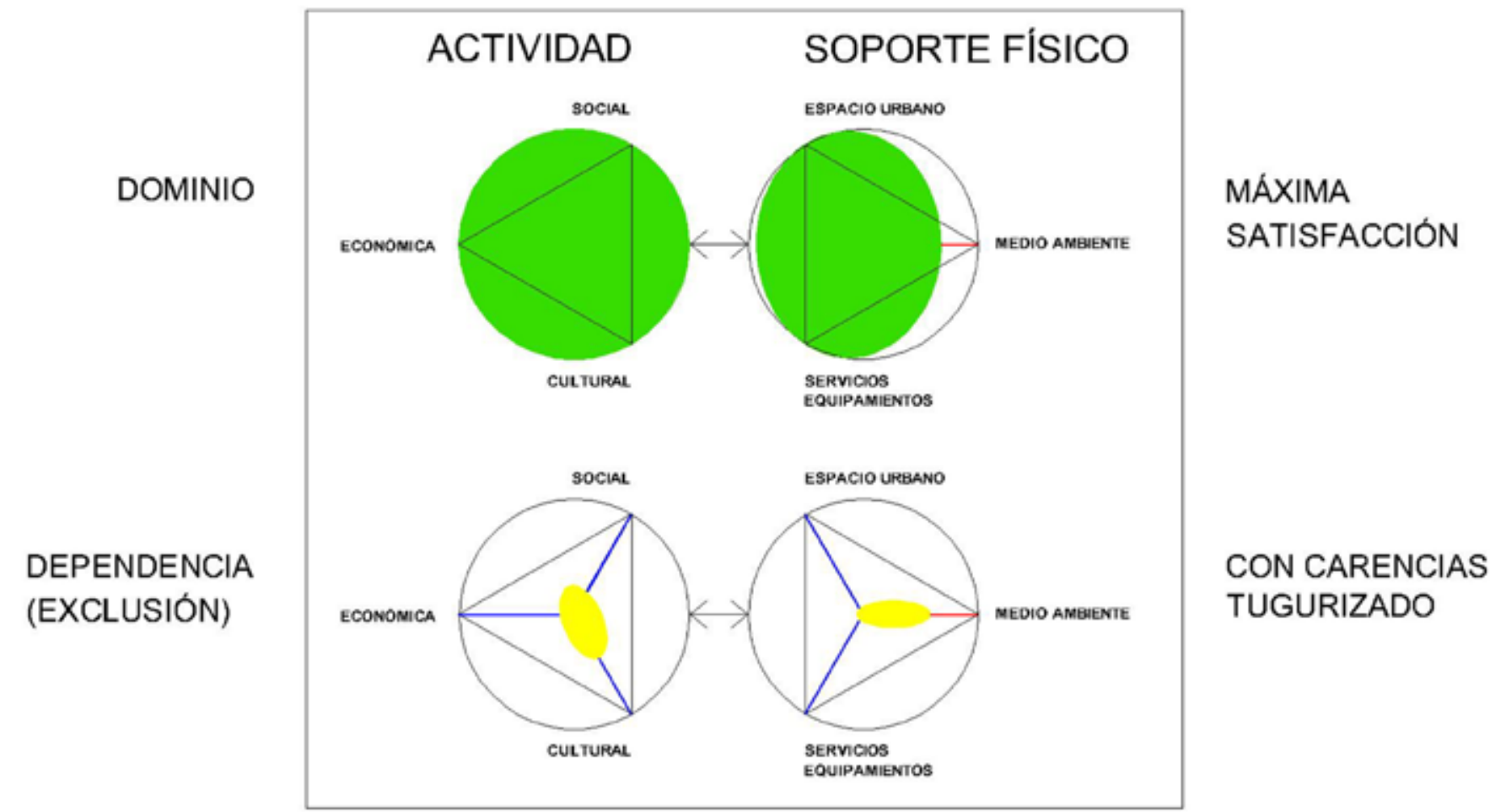

\subsection{Agentes que intervienen en el proceso}

En todo el proceso de producción y/o mejora del hábitat, y en especial, de la gestión de una ciudad o un barrio, es clave el papel que ejercen los agentes en presencia. El resultado, en un cierto momento, es la componente de las fuerzas en presencia. Estas fuerzas pueden actuar coincidiendo, sumando en una dirección o contraponiéndose o anulándose, logrando imponerse la o las predominantes a la acción de las contrarias.

Cuando las aspiraciones de las poblaciones para lograr un hábitat coinciden con las de otros agentes, políticos y técnicos fundamentalmente, se inician procesos de cooperación o colaboración que, si no se intentan dominar por los políticos (con políticas asistencialistas o populistas) o por los técnicos (con acciones tecnocráticas), pueden dar lugar a procesos de cogestión y de democracia participativa. El concepto de cogestión coincide con la proposición de Víctor Pelli del concepto de concertación:

El concepto de concertación implica, además de este reconocimiento de existencia, la propuesta de generar y jerarquizar una instancia de puesta en actores, con sus zonas de conflicto, así como de generar una dinámica de articulación y negociación que posibilite la búsqueda organizada de propuestas consensuadas y realmente factibles para las acciones de transformación (Pelli 2006, p. 68).

Cuando los políticos abandonan a las poblaciones, atendiendo a otros intereses propios o ajenos (del poder económico, por ejemplo) y los técnicos actúan por encargo de estos intereses, abandonando a su vez a las poblaciones, estas no tienen más salida que la autogestión y/o autoproducción de su propio hábitat. Esta es la situación para la mayoría de la población mundial.

Estos procesos no se desarrollan de la misma forma en cualquier si-
Figura 3. Síntesis de los factores que intervienen en el proceso de mejora y/o producción del hábitat. Situaciones posibles. Fuente: Elaboración propia. 


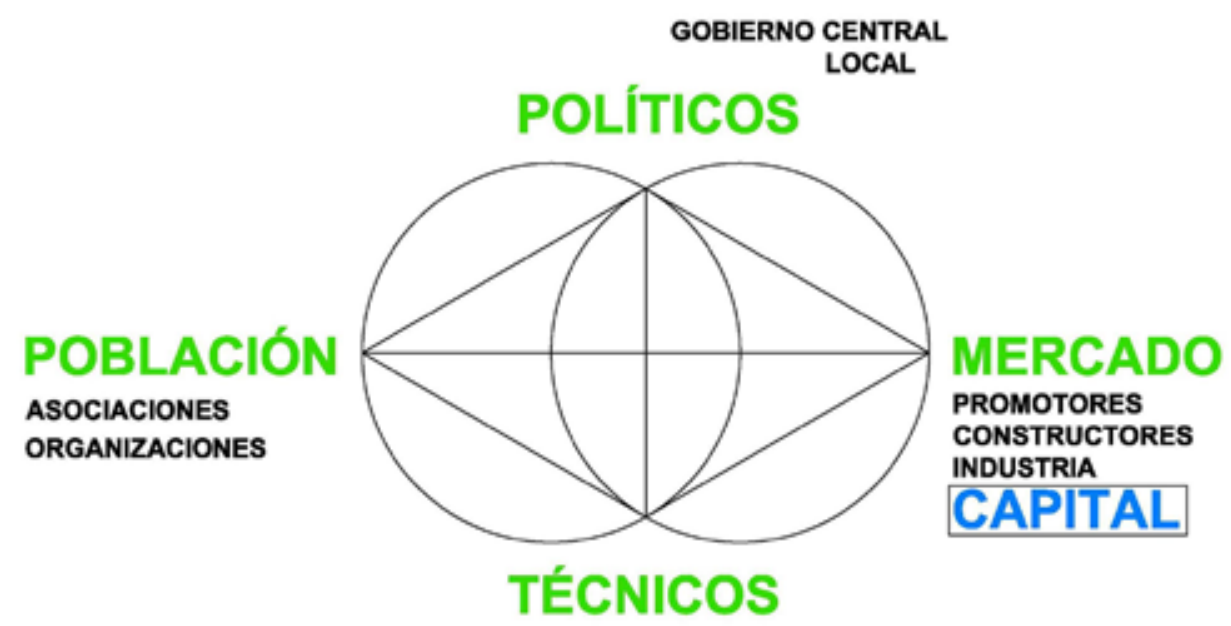

tuación o lugar, son muy distintos según la situación social, económica o cultural en la que se insertan. El proceso en una sociedad en crecimiento (África y Asia, por ejemplo) no es el mismo que en una sociedad estabilizada (muchos países de América) o en decrecimiento (países de Europa o Japón, por ejemplo). En los primeros está continuamente creándose ciudad, aumentándose el espacio edificado y creando hábitat nuevo. En los segundos hay un claro

Figura 4. Agentes que intervienen en el proceso de mejora y/o producción del hábitat, de la gestión de la ciudad o del barrio. Fuente: Elaboración propia. proceso de predominio de la mejora del hábitat existente, pudiendo controlarse la creación de ciudad nueva, pero con la presencia de la apetencia económica de apropiación del espacio ya construido (en lugares apetecidos, centrales o de periferia), con el objetivo de destruir lo existente y proponer vivienda nueva, especulativa, provocando procesos de erradicación de poblaciones. En los últimos, países en decrecimiento demográfico, el objetivo es la utilización del espacio vacío, la mejora o evolución del hábitat existente, pero con presencia predominante del poder económico.

Profundicemos en el papel de los agentes que intervienen en el proceso. ¿Quiénes son estos agentes? ¿Cuál es la relación entre ellos? ¿Cómo se toman las decisiones en esta relación y qué efectos tienen en la ciudad?

Como indica la figura 4, los agentes de la producción o mejora del hábitat son múltiples, pero podemos identificarlos con cuatro grupos:

- Población que utiliza la ciudad o el barrio, los ciudadanos que viven.

La población puede intervenir en las decisiones de la ciudad o del barrio a nivel personal, a través de sus representantes directos, o de asociaciones u organizaciones, propias o externas, que actúan en la ciudad o el barrio.

- Políticos, gobierno central y local elegidos por la población, gestores y administradores públicos de los intereses comunes.

- El mercado, el sector productivo o de inversión que actúa con el fin prioritario de obtener beneficio económico.

En primer lugar, los promotores privados, los constructores, la industria y el comercio. En segundo lugar, las compañías suministradoras de servicios e infraestructuras. En tercer lugar y muy importante, el capital como tal, el dinero que se plantea como objetivo de inversión la ciudad o el barrio.

- Los técnicos que pueden actuar como apoyo a cualquiera de los tres sectores indicados: técnicos de las poblaciones, de la administración central y local o técnicos del mercado.

Como indica la figura 5, la relación entre los agentes es muy compleja y produce una gama muy amplia de resultados. Esta relación se mueve entre dos modelos antagónicos que pueden tener y de hecho tienen una presencia simultánea en la ciudad. 


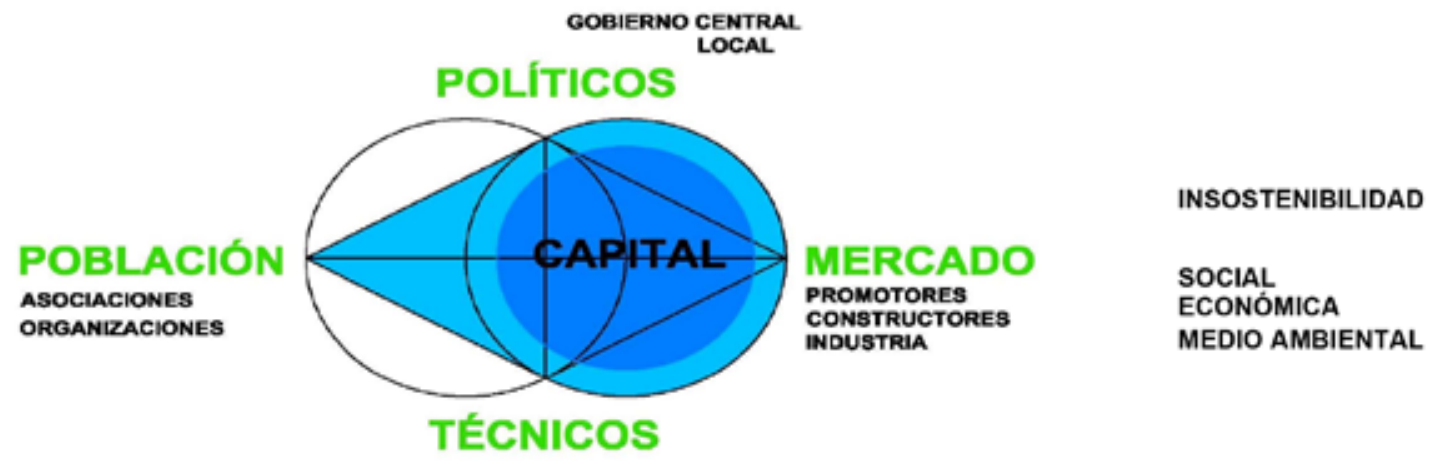

PREDOMINIO DE LA POBLACIÓN

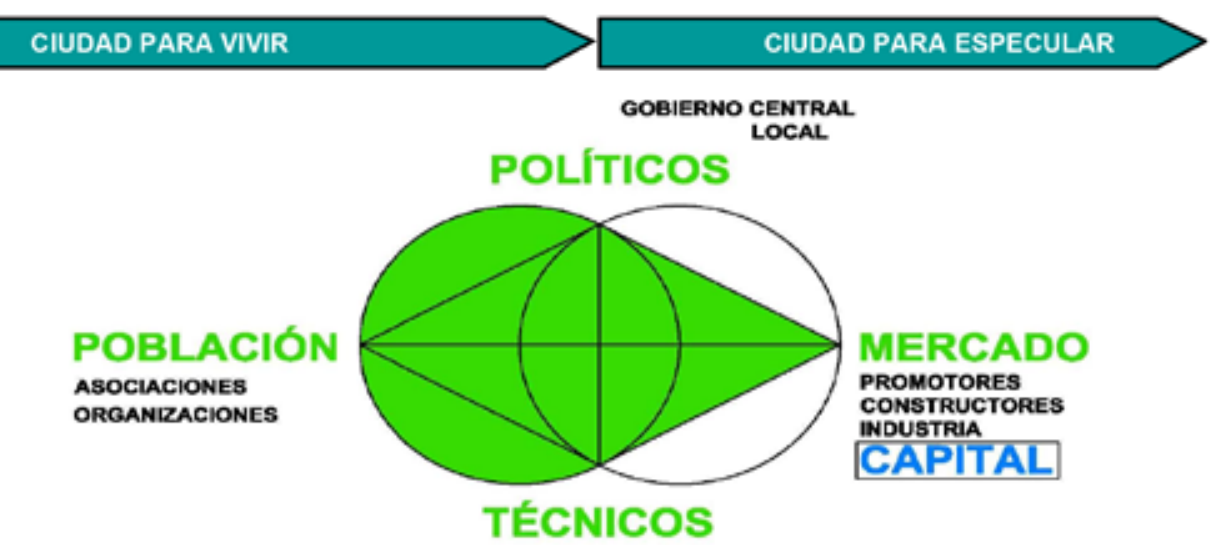

PREDOMINIO DEL MERCADO

PROCESO

PARA LA SOSTENIBILIDAD

\subsubsection{Modelo A. Predominio del mercado}

Las decisiones se toman predominantemente en el círculo formado por el mercado, los políticos y los técnicos, dominados por el mercado y en especial por el capital.

Los usuarios, la población, son tratados como simples clientes o ignorados cuando ellos mismos resuelven su problema residencial (exclusión social y económica).

El capital actúa creando deuda, dominando el crédito. Su objetivo es que la población, la familia, la industria, el comercio, la ciudad y el estado estén endeudados y captar el beneficio de la deuda.

El objetivo general es una ciudad o un barrio para especular.

Es un modelo especulativo con "forma" democrática. Una ciudad o un barrio dependiente del beneficio del dinero.

\subsubsection{Modelo B. Predominio del ciudadano}

Las decisiones se toman en el círculo formado por la población, los políticos que asumen el papel de representantes elegidos por los ciudadanos y los técnicos (de las poblaciones y de la administración).

El mercado, el sector productivo, tiene sus intereses, pero sometidos a los derechos generales sociales. El mercado es el cliente.

El objetivo es una ciudad para vivir y no una ciudad para especular.

En este modelo el capital debe ser obligado a actuar sin crear dependencia ciudadana, política o técnica.

Es un modelo democrático, representativo, pero con mecanismos de actuación u objetivos de democracia participativa.

Un extremo de predominio ciudadano se da, en la situación actual, en convivencia con el modelo de predominio del mercado. El ciudadano autogestiona y produce su propia ciudad o barrio, o edificio, con sus propios medios, utilizando el mercado productivo o produciendo,

Figura 5. Relación entre los agentes. Fuente: Elaboración propia. 
con sus medios económicos, pero ajeno o reduciendo al mínimo el uso del capital especulativo. Son ejemplos los asentamientos humanos y las cooperativas de vivienda.

\subsection{Mecanismos que se aplican en el proceso}

En los procesos de mejora y/o producción del hábitat; en los que el objetivo prioritario es la mejora de la calidad de vida, la ciudad o el barrio para vivir, se aplican múltiples mecanismos (teorías, políticas, programas, proyectos o técnicas).

Aunque la dimensión del artículo no permita un desarrollo de todos los conceptos, ni es necesario para los objetivos propuestos, su enunciado y recorrido permite observar la complejidad y variedad de los mecanismo que se aplican, la variedad del esfuerzo y el conocimiento desarrollado por diversos colectivos y en diversas situaciones, la ejemplaridad o capacidad de replicabilidad de estos mecanismos, así como su influencia en las diversas escalas de actuación.

\subsubsection{Teorías y conceptos}

Son múltiples en función de los intereses de los agentes en presencia:

- Derecho a la vivienda. Ya internacionalmente aceptado, pero con diferentes grados de aplicación.

- Derecho a la ciudad. En construcción de acuerdo con la Carta Mundial por el Derecho a la Ciudad.

- Producción social del hábitat:

Por producción social del hábitat entendemos todos aquellos procesos generadores de espacios habitables, componentes urbanos y viviendas, que se realizan bajo el control de autoproductores y otros agentes sociales que operan sin fines lucrativos.

Las modalidades autogestionadas incluyen desde la autoproducción individual espontánea de la vivienda hasta la colectiva, que implica un alto nivel organizativo de los participantes y, en muchos casos, procesos complejos de producción y gestión de otros componentes del hábitat (Ortiz y Lorena, 2002, p. 15).

- Habitabilidad Básica.

Es aquella que alcanza las condiciones mínimas e imprescindibles que garantizan el desarrollo de la vida socialmente considerada saludable en la actualidad y la reproducción normal de los pobladores (Salas et al., 2006, p. 5).

- Ecología. Relación del ser vivo con su medio.

Ecología Humana. Relación del ser humano con su medio.

- Sostenibilidad. Condiciones para que un sistema ecológico se desarrolle (no coincidente con el concepto de crecimiento) de acuerdo con su evolución futura.

Sostenibilidad del sistema ecológico humano: Debe contemplar la sostenibilidad social, económica, cultural, física y medioambiental. 
Para el concepto de sostenibilidad ver: Gallopin (2003) y AAVV (1997).

- Resiliencia. Capacidad de respuesta de un sistema ecológico a un estímulo externo. Capacidad de respuesta del sistema ecológico humano, de la ciudad por ejemplo, a procesos externos (negativos o positivos) para su adaptación o transformación, según los grados de incidencia del estímulo.

- Transición. Proceso necesario para que un hábitat (estado, ciudad, barrio) se adapte o transforme en búsqueda de su sostenibilidad.

- Desborde Urbano. Crecimientos no controlados socialmente.

Transformaciones no programadas ni diseñadas para la ciudad para vivir. Pueden ser sociales, económicas, culturales, físicas o medioambientales, provocadas por las condicionantes internas de la ciudad (crecimientos de población, evolución social...) o externas (imposiciones, localizaciones de actos como son las olimpiadas, industrias o empresas, o crecimientos especulativos artificiales como ha supuesto la burbuja inmobiliaria española).

Para el concepto de desborde urbano ver: Schelloto et. al., 2013.

- Participación/cogestión y autogestión. Es la capacidad de intervención de los distintos agentes y, en especial, de los ciudadanos, de los usuarios, en los procesos de mejora y/o construcción del hábitat.

\begin{tabular}{|ll|}
\hline Grados y tipos de participación & El usuario \\
\hline Producto técnico acabado & - Recibe \\
Distintos productos & - Elige \\
Información en el proceso & - Se le informa \\
Se pide su opinión en el proceso & - Se le consulta \\
\hline No vinculante & \\
Vinculante & \\
\hline Está representado en el proceso & - Cogestión representativa \\
Mesa de negociación & - Cogestión directa. Participativa \\
\hline Autogestión & - Autogestiona \\
\hline
\end{tabular}

Cuadro 1. Grados y tipos de participación. Fuente: Elaboración propia.

Los Gobiernos, generalmente locales, incluyen en sus programas y consideran que usan correctamente el concepto de participación, no es así, en general la participación se usa en los grados en los que el ciudadano es simplemente informado o consultado no vinculantemente, en definitiva, se aplica para justificar una acción autoritaria.

Los grados y tipos de participación pueden ser distintos (ver cuadro 1):

- Cuando se actúa directamente, realizando un producto técnico acabado (una plaza o un equipamiento, por ejemplo) el usuario simplemente recibe el producto y lo usa, o no.

- Ante la propuesta de varios productos realizados con un mismo objetivo, el usuario puede elegir. 
- El usuario puede ser informado de un proceso propuesto por otro agente (político o técnico en general) para la realización de algo que él usará. Por ejemplo, la mejora de una vía de circulación. El usuario recibirá la reforma sabiendo que se va a realizar pero sin influir en ella.

- Una situación habitual es consultar al usuario sin que sea vinculante su opinión. Aunque se pueda tener en cuenta, si lo creen conveniente los políticos o los técnicos. Son, en general, los casos de las mesas de participación ciudadana, no vinculantes, pero útiles para la justificación de las decisiones políticas.

- Cuando es vinculante, comienzan los grados y tipos de participación que se pueden considerar aceptables para el ciudadano.

En un primer grado, aún imperfecto, el ciudadano está representado por sus organizaciones y asociaciones, o por técnicos que trabajan con ellos. Es una mesa de cogestión representativa.

En un segundo grado, el ciudadano se representa a sí mismo, así como las asociaciones y organizaciones, en un proceso de cogestión directa, participativa. Son las mesas de participación o concertación, vinculantes.

Como ya se ha indicado, cuando los políticos y los técnicos desatienden a los ciudadanos, estos optan por la autogestión, por resolver su problema de hábitat con sus propios medios.

La autogestión del usuario no es participación. Un ejemplo es la actual proposición y realización de la ciudad desde la propia iniciativa (asentamientos humanos o cooperativas).

- Flexibilidad. La flexibilidad es un concepto, amplio y eficaz, aplicado por los distintos agentes, tanto políticos como técnicos, usuarios y productores para adaptar las soluciones de hábitat a las circunstancias del lugar, en continua transformación.

El concepto de flexibilidad se aplica con diversos objetivos:

- Flexibilidad de uso. Las condiciones sociales, económicas y culturales de las poblaciones están en continua evolución, a todas las escalas. Una vivienda bien realizada se adaptará o alojará correctamente al grupo humano que la habita en diversos momentos (primera ocupación, crecimiento, crecimiento de hijos, llegada de parientes, marcha de hijos...) y en las diversas situaciones económicas.

Esta evolución se aplica con dos mecanismos: elasticidad (o cambio de la dimensión de los espacios) y adaptabilidad (adecuación de los espacios a los distintos usos).

- Flexibilidad del proyecto. Supone trabajar con las necesidades y posibilidades genéricas de los grupos humanos (familias, por ejemplo) y del lugar donde se actúa, adaptándolas, cuando se va a realizar el espacio, a las necesidades y posibilidades concretas del grupo humano concreto.

Es un mecanismo fundamental para la práctica del diseño participativo, tanto urbano como edificatorio.

- Flexibilidad técnica. En el transcurso de la vida del hábitat, evoluciona tanto la economía como la tecnología. La solución habitacional se adaptará en el tiempo a esta evolución de dos formas: sustituyendo las tecnologías desaparecidas o evolucionadas (una solución de techo, por ejemplo) o buscando una progresividad cualitativa (ver progresividad). 
- Progresividad. En el proceso de producción social del hábitat, normalmente, no se piensa (proyecta) y realiza el espacio acabado y luego se habita, ni el barrio, ni la vivienda. Ambos se realizan progresivamente según procesos que pueden durar décadas. Esta progresividad puede ser de dos tipos: progresividad espacial, en la que la vivienda, por ejemplo, va creciendo y adaptándose a la evolución del grupo que la habita y progresividad cualitativa, en la que la ciudad, el barrio o la propia vivienda va mejorando cualitativamente en el tiempo. La ciudad, precaria al principio, puede ir incorporando servicios o equipamientos. En el caso de la vivienda, una primera situación precaria del muro de cerramiento o de la cubierta puede perfeccionarse dotándoles de asilamiento o nuevas capas en su tiempo de vida o, por ejemplo, se pueden mejorar las instalaciones.

\subsubsection{Políticas habitacionales}

La política habitacional es un mecanismo clave en el proceso de mejora y/o producción del hábitat en un país, ciudad o barrio.

\begin{tabular}{|c|c|}
\hline \multicolumn{2}{|c|}{ Políticas habitacionales. Estado liberal (neoliberal) } \\
\hline $\begin{array}{l}\text { Estado social } \\
\text { - Benefactor } \\
\text { - Proveedor de bienes y servicios } \\
\text { - Estado responsable }\end{array}$ & $\begin{array}{l}\text { Libre mercado } \\
\text { Promoción pública } \\
\text { Legislación marco de viviendas so- } \\
\text { cial }\end{array}$ \\
\hline $\begin{array}{l}\text { Estado facilitador } \\
\text { - Políticas alternativas } \\
\text { - Participación }\end{array}$ & $\begin{array}{l}\text { Reconocimiento de la capacidad de } \\
\text { organización gestión social, de la } \\
\text { producción social. } \\
\text { Mecanismos alternativos. Progra- } \\
\text { mas y proyectos controlados }\end{array}$ \\
\hline $\begin{array}{l}\text { Estado redistribuidor } \\
\text { - Integrador } \\
\text { - Estado corresponsable } \\
\text { - Cogestión }\end{array}$ & $\begin{array}{l}\text { Corresponsabilidad social } \\
\text { Necesidad de decidir juntos } \\
\text { Democracia participativa } \\
\text { Integración e inclusión social }\end{array}$ \\
\hline
\end{tabular}

Cuadro 2. Políticas habitacionales. Fuente: Elaboración propia.

Una política habitacional plantea, a partir de unos criterios e ideologías, los objetivos para la mejora y/o producción del hábitat, los medios y la manera para conseguirlos, organizando a los actores que intervienen y gestionando los procesos que se proponen. Una política debe definir una estrategia flexible, adaptable a las distintas circunstancias para conseguir los resultados.

Aunque la realidad es muy compleja y depende de las situaciones y de los grupos políticos locales, en el panorama de las políticas habitacionales contemporáneas pueden identificarse cuatro grandes familias de distintas políticas que se enmarcan, actúan o son consecuencia del modelo de Estado en el que se desarrollan. En muchos casos, estas políticas responden a una evolución local, en otros pueden convivir en un mismo país o región, aplicadas a distintas escalas (ver cuadro 2).

Estas cuatro grandes familias son:

- Estado Liberal. Aplica políticas neoliberales con predominio del 
mercado y el capital. Son las predominantes a nivel mundial. El modelo se está fortaleciendo y aumentando.

Es común que aparentes políticas sociales de mejora de la ciudad o de respuesta a las necesidades de vivienda, dejen el desarrollo de los programas que proponen en manos de los promotores privados, del capital, convirtiendo a los usuarios en simples clientes que no encuentran el hábitat que necesitan o al que podrían optar, obligándoles a elegir entre lo que les ofrece el mercado o la autogestión de su propio hábitat.

- Estado Social. Actúa con consciencia de las carencias habitacionales, normalmente cuantitativas, pero considera que es un problema propio al que debe dar solución con sus propios medios y autoridad. Aunque es consciente de la necesidad del reequilibrio social y económico, no identifica ni favorece las capacidades que tienen las poblaciones para aportar soluciones y medios, económicos y humanos.

Es un Estado proveedor de bienes y servicios dirigidos a resolver ciertos problemas que el mismo Estado identifica, es un Estado que asume sin participación operativa la responsabilidad social.

Es el Estado benefactor.

- Estado Facilitador. Es consciente de la capacidad que tienen las poblaciones de aportar soluciones y medios. Tanto materiales como humanos, para la solución de su propio hábitat.

El Estado (o el poder político local) considera estas aportaciones como acciones importantes para la solución de la mejora del hábitat y las facilita con programas y con medios económicos específicos, condicionando las soluciones, asistiendo técnicamente, pero aceptando la participación ciudadana.

El Estado reconoce la oportunidad que significa la capacidad de autogestión de las poblaciones y diseña políticas que favorecen la participación ciudadana, políticas de corresponsabilidad pero diseñadas desde el Estado. La participación no se plantea en el diseño de las políticas y de los programas sino en su aplicación. Es una política participativa parcial o limitada.

- Estado Redistribuidor, Integrador. Tiene como objetivo el reequilibrio social, económico y cultural, y como método aplica la corresponsabilidad real de los actores, la aplicación de la gestión social y la economía social. El método es la democracia participativa, tanto en el diseño de las políticas como en su aplicación.

Actualmente se aplica a pequeña escala, en lugares concretos o para resolver proyectos concretos, pero es posible su expansión y aplicación a mayor escala. Se está aplicando para la mejora de asentamientos humanos dentro del cambio de paradigma que se ha producido en los diez últimos años en América Latina, donde se ha evolucionado desde las políticas de "tabla rasa" a las políticas de rehabilitación y mejora manteniendo la estructura existente.

Es la política de referencia para conseguir una ciudad sostenible.

Coincidiendo con estas cuatro familias Rubén Sepúlveda y Raúl Fernández Wagner (2006), en esquema, proponen para América Latina las siguientes políticas habitacionales (coincidentes con etapas históricas): 1. Globalización. 2. Estado protector, benefactor, promotor, clien- 
talista (primera generación). 3. Estado facilitador. Acompaña, asiste y organiza (segunda generación). 4. Estado redistribuidor. Políticas de regularización de asentamientos (tercera generación, últimos 15 años).

En España las políticas de vivienda, a partir de la desaparición de la Dictadura, han fluctuado entre un Estado liberal puro y un Estado social, según el partido que gobierna, pero con defectos comunes, como son entender la producción de vivienda como una "locomotora económica" prioritaria, y el hábitat, las ciudades y los barrios como ámbitos del mercado y la inversión potenciando un país de propietarios. Todo esto agravado por la consideración del turismo como sector básico, depredador de pueblos y costas.

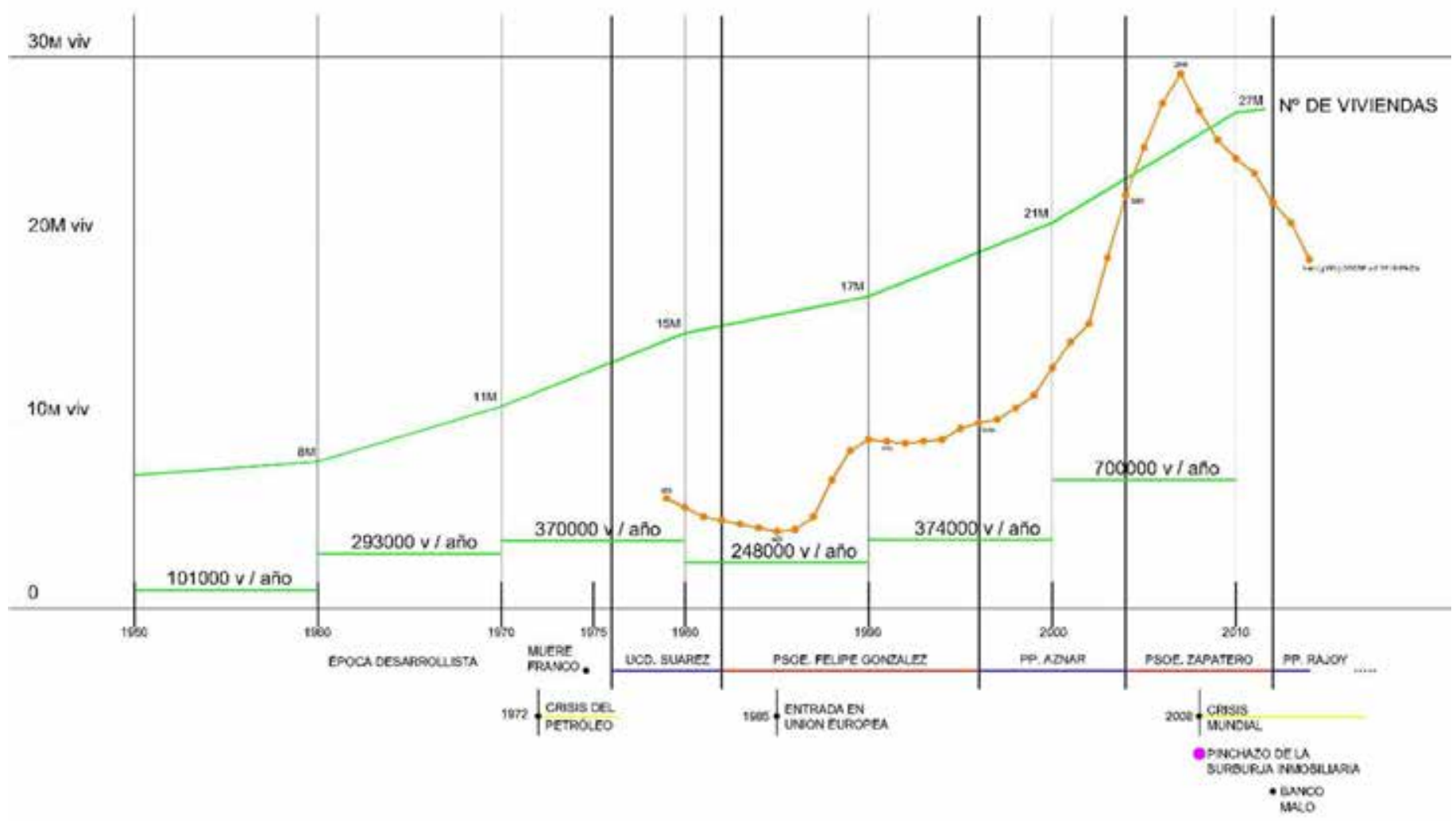

Las consecuencias de este modelo productivo han sido:

- Aumento de coste de la vivienda, por encima de su valor.

- Exceso de producción de vivienda.

- Producción de vivienda deslocalizada, en lugares donde no se necesita y para colectivos que no la necesitan condenando a sectores de población a una situación sin solución de vivienda.

- Predominio de vivienda para invertir, no para habitar.

- Creación de la burbuja inmobiliaria.

El pinchazo de la burbuja inmobiliaria tiene como consecuencia específica la gran producción de vivienda vacía, de espacio vacío en muchos casos inacabado (ver ejemplo 1 ).

En España las políticas de hábitat siempre se han movido dentro de las dos primeras familias, no llegando nunca a políticas de Estado facilitador y menos de Estado distribuidor. La contradicción y limi-
Figura 6. El modelo productivo de vivienda en España. Fuente: Elaboración propia. 
tación se refleja ahora, actualmente, cuando frente al bipartidismo representante de las dos primeras formas políticas, surgen los movimientos alternativos representantes de la cuarta forma, la democracia participativa, el Estado distribuidor. Falta el eslabón intermedio; están muy alejados.

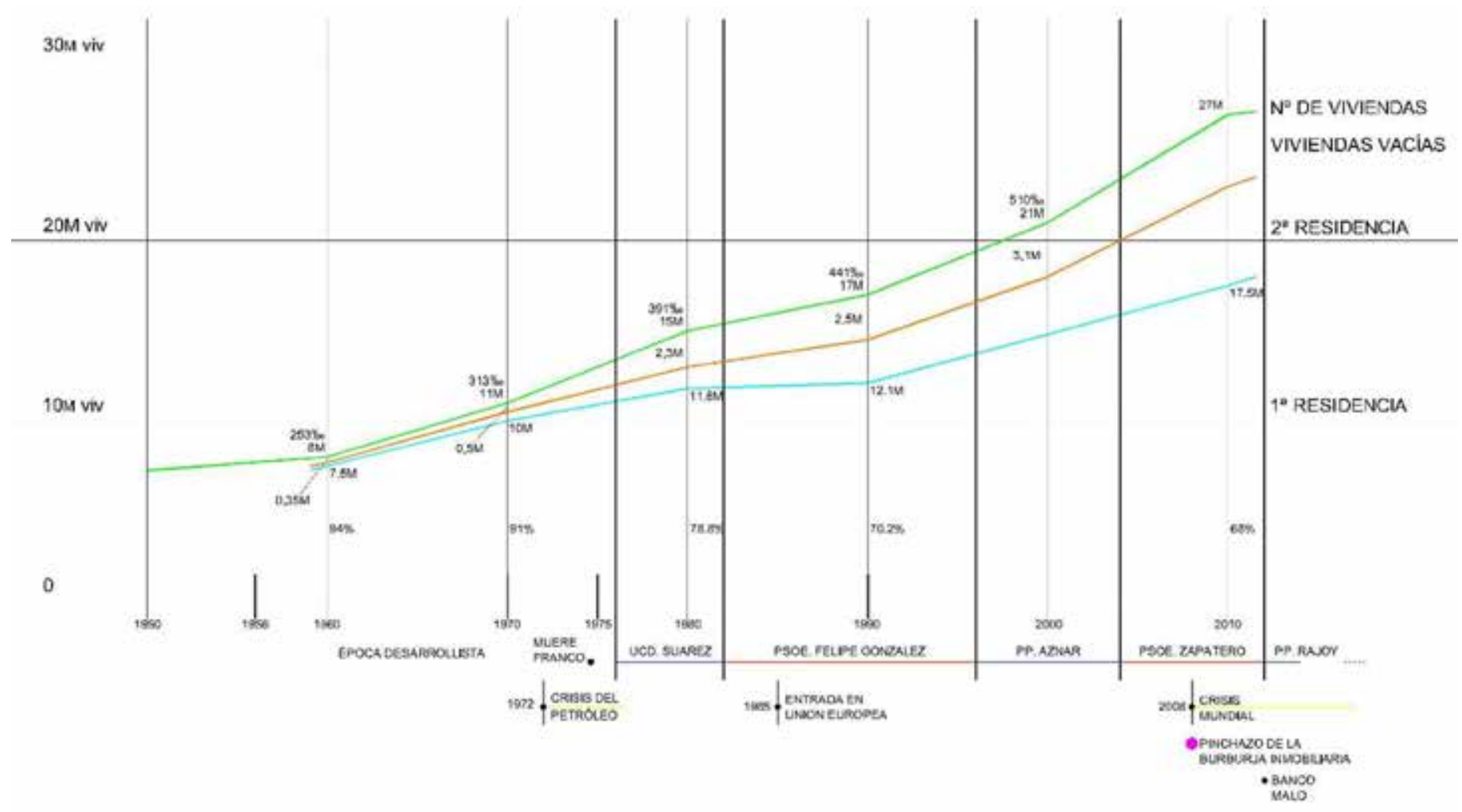

Figura 7. Producción de vivienda vacía en España. Fuente: Elaboración propia.

\subsubsection{Programas}

Un programa es la ordenación de acciones para conseguir el objetivo de la mejora o producción del hábitat en un período de tiempo (varios años) y en un área generalmente amplia (ciudad, departamento, áreas rurales, país o conjunto de países).

\subsubsection{Proyectos}

Son acciones concretas, pueden ser de dos tipos:

- Proyectos Ciudad. En los que se aborda principalmente el espacio urbano, la accesibilidad, las infraestructuras, los servicios y los equipamientos, buscando el fortalecimiento social a través de la participación, la formación y capacitación y el acceso al mercado de trabajo.

- Proyectos Vivienda. En los que se plantea prioritariamente la mejora o construcción de vivienda, sin renunciar a los servicios necesarios y la mejora barrial, con los mismos objetivos que los proyectos ciudad.

\subsubsection{Técnicas}

Las áreas tecnológicas que intervienen en la mejora y producción 
social del hábitat pertenecen a diversas disciplinas que será necesario aplicar y que serán objeto de enseñanza.

Estas áreas son:

- Técnicas de fortalecimiento social e institucional.

- Proceso de Mejora y Producción de Hábitat.

- Organización/Asociación.

- Gestión.

- Participación.

- Formación y Capacitación.

- Técnicas económicas.

- Acceso al hábitat: propiedad, alquiler...

- Obtención del máximo rendimiento de la propia capacidad económica.

- Potenciación de la capacidad de ahorro y crédito. Creación de sociedades intermedias.

- Técnicas legales. El principal objetivo es conseguir la tenencia segura del hábitat.

- Técnicas de producción.

- Proyecto del hábitat (Participación de los pobladores, Proyecto Participativo, urbano o edificatorio).

- Producción y/o acceso a los materiales, componentes, elementos y sistemas constructivos (Talleres básicos. Microproducción. Banco de Materiales).

- Construcción del hábitat (Técnicas y sistemas constructivos, organización y seguimiento del proceso).

\section{La escala como factor del proceso}

Dentro de una misma situación social, económica y cultural, un país o un área geográfica, los procesos de mejora y/o construcción del hábitat no se realizan de una manera unívoca. En ellos influyen múltiples factores, desde cuál es la componente predominante de las fuerzas en presencia, de quién toma la iniciativa (quién promueve), de los intereses de los agentes y evidentemente, de la escala a la que se actúa.

No son lo mismo, en el ámbito del hábitat, las actuaciones a nivel mundial, como pueden ser la construcción y aceptación del derecho a una vivienda digna, aunque se aplique (o no se aplique) de diversas maneras, o el derecho a la ciudad, en construcción, que las actuaciones en las áreas regionales (Europa o Mercosur, por ejemplo), en las zonas de identificación geográfica (como la vivienda andina, por ejemplo), en los Estados o naciones, en las áreas rurales o en las ciudades, en los barrios o en los asentamientos, así como en actuaciones concretas (terrenos o edificios).

¿Cuál es la capacidad de intervención de los distintos agentes en estas escalas?

¿Cuál es la capacidad de influencia eficaz de las poblaciones, para conseguir un hábitat no precario, en estas escalas?

¿Cuál es la posibilidad de cualificación y asistencia (legal, económica y técnica) de los procesos de autogestión como forma cuantitativamente prioritaria de producción del hábitat, en estas escalas? 


\section{Relación de las variables (factores, agentes y mecanismos) con la escala de intervención, para la mejora y/o producción del hábitat}

Para observar esta relación se propone el análisis de distintos ejemplos de intervención. Los ejemplos se han escogido en el ámbito de España, donde coinciden una situación de crisis económica y el "estallido de la burbuja inmobiliaria”, ambos a partir del 2007, situación en la que actualmente está sumergido el país, Estos ejemplos son representativos de los modelos y mecanismos empleados así como de los inicios de propuestas alternativas, en casos aprendidas de otras situaciones y lugares.

Los ejemplos podrían ser muchos pero han sido seleccionados (lo que significa una elección y sesgo de la realidad) como representativos de las escalas, agentes y mecanismos en presencia.

Se proponen:

- Ejemplo 1. Producción de vivienda vacía en España (cuadro 3).

- Ejemplo 2. Ocupación de edificios nuevos vacíos (cuadro 4).

- Ejemplo 3. PAH. Plataforma Afectados por la Hipoteca (cuadro 5).

- Ejemplo 4. Gamonal, Burgos (cuadro 6).

- Ejemplo 5. Marinaleda, Sevilla (cuadro 7).

- Ejemplo 6. Cooperativas de vivienda (cuadro 8).

- Ejemplo 7. Ley de costas (cuadro 9).

\subsection{Ejemplo 1. Producción de vivienda vacía en España}

\begin{tabular}{|c|c|c|c|c|c|c|c|c|c|c|c|c|c|c|c|c|c|c|c|c|c|c|c|c|c|c|c|c|c|c|c|c|c|}
\hline \multicolumn{32}{|c|}{ Variables analizadas } & & \\
\hline \multicolumn{8}{|c|}{ Escala } & \multicolumn{6}{|c|}{ Factores que intervienen } & \multicolumn{5}{|c|}{ Agentes que intervienen } & \multicolumn{13}{|c|}{ Mecanismos que intervienen } & & \\
\hline \multirow{6}{*}{$\frac{\pi}{\frac{\pi}{0}}$} & \multirow[b]{3}{*}{ 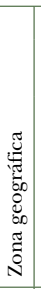 } & \multirow[b]{3}{*}{$\stackrel{\infty}{\tilde{E}}$} & \multirow[b]{3}{*}{$\begin{array}{l}0 \\
80 \\
\check{0} \\
\check{\simeq}\end{array}$} & \multirow[b]{3}{*}{$\begin{array}{l}\vec{J} \\
\stackrel{\vec{J}}{0} \\
:\end{array}$} & \multirow[b]{3}{*}{$\stackrel{\mathscr{E}}{\mathscr{E}}$} & \multirow[b]{3}{*}{ 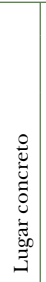 } & \multirow[b]{3}{*}{ 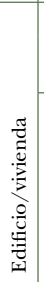 } & \multirow{2}{*}{\multicolumn{3}{|c|}{$\begin{array}{l}\text { Actividad } \\
\text { humana }\end{array}$}} & \multirow{2}{*}{\multicolumn{3}{|c|}{$\begin{array}{l}\text { Soporte } \\
\text { físico }\end{array}$}} & \multirow[b]{3}{*}{$\mid$} & \multirow[b]{3}{*}{$\begin{array}{l}\stackrel{8}{0} \\
\stackrel{\Xi}{\Xi} \\
\stackrel{0}{0}\end{array}$} & \multirow[b]{3}{*}{ 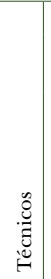 } & \multirow[b]{3}{*}{ 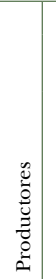 } & \multirow[b]{3}{*}{ 胥 } & \multirow[b]{3}{*}{ 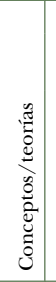 } & \multirow[b]{3}{*}{$\begin{array}{l}\stackrel{\tilde{g}}{:} \\
\stackrel{\Xi}{0} \\
2\end{array}$} & \multirow[b]{3}{*}{ 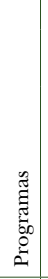 } & \multirow[b]{3}{*}{ 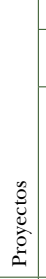 } & \multicolumn{9}{|c|}{ Técnicas } & & \\
\hline & & & & & & & & & & & & & & & & & & & & & & & \multicolumn{6}{|c|}{ Sociales } & \multicolumn{3}{|c|}{ Construcción } & & \\
\hline & & & & & & & & 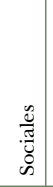 & 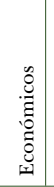 & $\begin{array}{l}\frac{\mathscr{U}}{\tilde{n}} \\
\frac{\tilde{E}}{\Xi} \\
\tilde{\Xi}\end{array}$ & 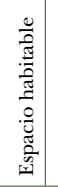 & $\begin{array}{l}0 \\
\stackrel{0}{0} \\
\stackrel{0}{n} \\
\infty\end{array}$ & 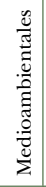 & & & & & & & & & & 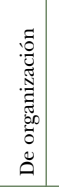 & 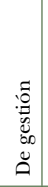 & 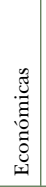 & 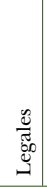 & 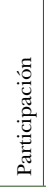 & 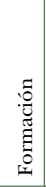 & 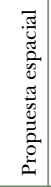 & 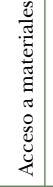 & 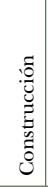 & & \\
\hline & & & & & & & & & & & & & & & & & & & & & & & & & & & & & & & & Autogestión & \multirow{2}{*}{ Para vivir } \\
\hline & & & & & & & & & & & & & & & & & & & & & & & & & & & & & & & & Cogestión & \\
\hline & & & & & & & & & & & & & & & & & & & & & & & & & & & & & & & & Imposición & Para \\
\hline
\end{tabular}

Cuadro 3. Ejemplo 1. Producción de vivienda vacía en España. Fuente: Elaboración propia.
La crisis económica actual, de alcance mundial y de gran incidencia en Europa, está acompañada en España por una crisis del sector inmobiliario: "la burbuja inmobiliaria" (Ver políticas habitacionales en Espana). El tema es muy complejo, a la vez que claro en su realidad actual (casi total paralización del sector, con desaparición de mas de 4000 inmobiliarias y una reducción de más del $70 \%$ de los proyectos de futuras viviendas, cambio de modelo de país de propietarios a país de inquilinos en régimen de alquiler, cuestionamiento de la edificación como locomotora económica...). Una de las consecuencias de la "burbuja inmobiliaria" ha sido un exceso de producción de vivienda para el mercado, dirigida a la inversión (el aumento de coste de la vivienda, artificial, de mercado, fue durante los años previos a la crisis muy superior al aumento del índice de crecimiento económico, lo que parecía asegurar un gran beneficio a la inversión, muy superior a la inversión en bolsa o en la industria). Este exceso de producción tuvo dos consecuencias: 
- Al ser dirigida a la inversión, no tenía como objetivo alojar a las poblaciones con necesidad de vivienda. El resultado es un alto porcentaje de vivienda (aproximadamente un 20\%) que nunca ha sido habitada, mientras que a un alto porcentaje de la población (aproximadamente un $30 \%$ en el que están comprendidos los jóvenes, los migrantes y otros sectores económicamente débiles) le era, y le es, imposible acceder a una vivienda.

- La gran producción de vivienda vacía, a múltiples escalas, desde pequeñas promociones hasta barrios enteros, sin ninguna esperanza de venta por efecto de la crisis y por el estallido de la "burbuja", ha supuesto una bajada continua de precio de la vivienda y una retracción de la inversión al perder la esperanza de beneficio. La vivienda nueva libre en España, en 2013, bajó un 13\% con respecto a los valores de 2007. La bajada fue mayor para la vivienda de segunda mano: $43 \%$. Actualmente siguen bajando los precios.

Una consecuencia inmediata de la gran producción de vivienda sin vender, ha sido el endeudamiento de los promotores ante la incapacidad del retorno de los créditos y el paso de cantidad de vivienda vacía a los bancos suministradores de crédito, dando lugar a la creación de un "banco malo"; el SAREB, que integra a 14 entidades que acaparan el 55\% del banco, siendo el otro $45 \%$ del FROB (Fondo de Restructuración Ordenada Bancaria), fondo estatal de dinero público que ayuda al saneamiento del sector financiero.

En el SAREB se acumula gran parte de del exceso de vivienda, lo que algunos llaman "activos tóxicos" vinculados al ladrillo (80000 millones de euros).

En un país con un grave problema de acceso a la vivienda y de exclusión social, hay una parte importante del patrimonio residencial que está infrautilizado, más o menos el mismo que necesitarían los sectores que no tienen acceso a la vivienda: tres millones de viviendas vacías para ocho millones de españoles a los que no les llegan las políticas sociales de la vivienda (Montaner y Muxi, 2011).

La "burbuja" inmobiliaria en España (ver figura 6)

La "burbuja inmobiliaria" se inicia en 1997 o antes, se prolonga hasta agosto del 2007 (con una elevación sostenida de los precios del $10 \%$ anual). El pinchazo se produce a finales del 2007.

El precio de la vivienda aumenta un $150 \%$ en el periodo de 1997-2007.

Entre 1999 y 2000 se producen 500000 viviendas al año.

Entre 2001 y 2005 se proyectan 800000 viviendas al año. No todas se construyen, pero se acaban 525000 (2003); 586000 (2004) y 612000 (2005) por ejemplo.

Solo parte se vende: 295000 (2004) y 336000 (2005); por ejemplo, lo que supone una acumulación de vivienda vacía. Las viviendas vacías estimadas son 690000 nuevas y 620000 de segunda mano (2009). Hay estudios que aumentan muy significativamente estas cifras, hasta 3000000 de vivienda vacías.

Algunos casos de producción masiva vacía en España.

- Castellón. Es la provincia con más vivienda nueva vacía en España (115000 en 2013).

- Boera Park. 264 viviendas, 26 habitadas.

- Moncofa. Municipio de 7000 habitantes. Se han construido 8000 viviendas (120000 proyectadas). Múltiples edificios de 12 plantas donde casi no vive nadie. En uno de ellos vive una persona. Hay múltiples estructuras paradas sin acabar.

- Cataluña. Unas 80000 viviendas sin vender.

- Mirador el Ebro. L'Aldea. Tarragona (localidad de 3500 habitantes). 
La urbanización Mirador del Ebro propone 1318 viviendas que provocan una excesiva activación en la zona. Ahora es un barrio fantasma, vallado. Hay viviendas con dueño pero sin servicios, no pueden vivir.

En 2006 y 2007 se inician 1500 viviendas en L'Aldea. Ahora hay múltiples estructuras paradas.

- Torre de Capdella. En Lleida (700 habitantes) se ponen en marcha 1085 viviendas. Están paradas.

- En Tortosa hay 4400 viviendas vacías.

- Lugo. Costa virgen de Barreiros (3200 habitantes).

Se otorgan licencias para 5800 nuevas viviendas. Muchas vacías, otras sin acabar o en estructura. Se permitió construir en cualquier terreno, incluso rústico, sin servicios básicos.

- Toledo. Seseña.

Famosa por la urbanización "Residencial Francisco Hernando" (nombre del llamado Paco el Pocero). Se proyectan 13000 viviendas. Se construyen 5000 ; los bancos se quedan con 2000 . La población de Seseña pasó de 6500 habitantes (2003) a 13000 (2006). Se quería llegar a 60000 (2011).

Estas llamadas "urbanizaciones fantasmas" son, de hecho, un claro ejemplo de desborde urbano físico, que multiplica, artificialmente y con el único objetivo del beneficio económico, el espacio urbano necesario, de una manera irresponsable y generadora de una necesidad de multiplicación de los servicios públicos, estos sí, socializados o producidos con recursos públicos, con una destrucción de los recursos rurales, del entorno de la ciudades y pueblos. Son, posiblemente, el peor ejemplo de urbanización "planificada" y en la mayoría de los casos legalizada, en connivencia con el poder político y con la asesoría de los técnicos.

Evidentemente, aunque son ejemplos extremos, no son los únicos ni la única escala de actuación. En la escala media y en la pequeña escala proliferan los ejemplos de vivienda vacía, producida para la especulación económica.

\subsection{Ejemplo 2. Ocupación de edificios nuevos, vacíos, en España}

\begin{tabular}{|c|c|c|c|c|c|c|c|c|c|c|c|c|c|c|c|c|c|c|c|c|c|c|c|c|c|c|c|c|c|c|c|c|c|}
\hline \multicolumn{32}{|c|}{ Variables analizadas } & & \\
\hline \multicolumn{8}{|c|}{ Escala } & \multicolumn{6}{|c|}{ Factores que intervienen } & \multicolumn{5}{|c|}{$\begin{array}{l}\text { Agentes que inter- } \\
\text { vienen }\end{array}$} & \multicolumn{13}{|c|}{ Mecanismos que intervienen } & & \\
\hline \multirow{6}{*}{$\frac{\pi}{\frac{\pi}{0}}$} & \multirow[b]{3}{*}{ 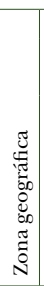 } & \multirow[b]{3}{*}{$\stackrel{n}{2}$} & \multirow[b]{3}{*}{ 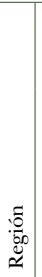 } & \multirow[b]{3}{*}{$\begin{array}{l}\vec{\pi} \\
\stackrel{\pi}{0} \\
0\end{array}$} & \multirow[b]{3}{*}{$\stackrel{\circ}{\stackrel{\Xi}{\Xi}}$} & \multirow[b]{3}{*}{ 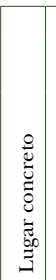 } & \multirow[b]{3}{*}{ 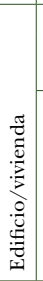 } & \multirow{2}{*}{\multicolumn{3}{|c|}{$\begin{array}{l}\text { Actividad } \\
\text { humana }\end{array}$}} & \multirow{2}{*}{\multicolumn{3}{|c|}{$\begin{array}{l}\text { Soporte fí- } \\
\text { sico }\end{array}$}} & \multirow{3}{*}{\multicolumn{2}{|c|}{ 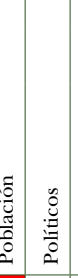 }} & \multirow[b]{3}{*}{ 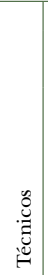 } & \multirow[b]{3}{*}{$\left|\begin{array}{l}0 \\
0 \\
0 \\
\mathscr{Z} \\
\tilde{Z} \\
0 \\
0\end{array}\right|$} & \multirow[b]{3}{*}{ : } & \multirow[b]{3}{*}{ 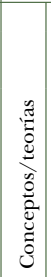 } & \multirow[b]{3}{*}{$\begin{array}{l}\stackrel{\mathscr{Z}}{G} \\
: \\
0\end{array}$} & \multirow[b]{3}{*}{ 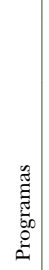 } & \multirow[b]{3}{*}{ 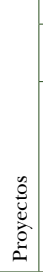 } & \multirow{2}{*}{\multicolumn{9}{|c|}{$\begin{array}{l}\text { Técnicas } \\
\text { Sociales }\end{array}$}} & & \\
\hline & & & & & & & & & & & & & & & & & & & & & & & & & & & & & & & & & \\
\hline & & & & & & & & 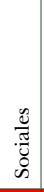 & 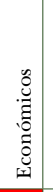 & 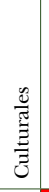 & 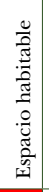 & 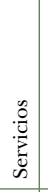 & 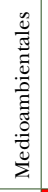 & & & & & & & & & & 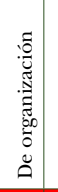 & 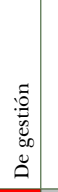 & 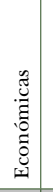 & 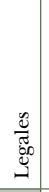 & 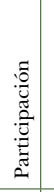 & 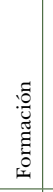 & 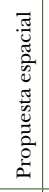 & 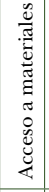 & 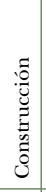 & & \\
\hline & & & & & & & & & & & & & & & & & & & & & & & & & & & & & & & & Autogestión & \multirow{2}{*}{ Para vivir } \\
\hline & & & & & & & & & & & & & & & & & & & & & & & & & & & & & & & & Cogestión & \\
\hline & & & & & & & & & & & & & & & & & & & & & & & & & & & & & & & & Imposición & \multirow{2}{*}{$\begin{array}{l}\text { Para } \\
\text { negociar }\end{array}$} \\
\hline & & & & & & & & & & & & & & & & & & & & & & & & & & & & & & & & & \\
\hline
\end{tabular}

Cuadro 4. Ejemplo 2. Ocupación de edificios nuevos, vacíos, en España. Fuente: Elaboración propia.
Como reacción a la construcción masiva de vivienda para el mercado, ajeno a la necesidad real de vivienda, a la capacidad económica de la población y al régimen de tenencia posible (alquiler en lugar de venta), se han creado múltiples iniciativas con un doble objetivo: resolver 
el problema concreto de ciertas poblaciones y demostrar la situación absurda creada.

Ejemplo de iniciativas ciudadanas son:

- Las Corralas de Sevilla (ciudad y provincia).

En Sevilla, en el 2012 se ocupa un edificio nuevo por 20 familias (36 cuando se ocupó por completo): la Corrala Utopía. Después de dos años fue desalojada.

En la actualidad el ejemplo se extiende a otras corralas. Entre ellas la Corrala Resistencia, donde se llegan a conseguir principios de acuerdo de "alquiler social" beneficioso para las familias y solución para promotores y bancos.

Otros ejemplos son la Corrala Conde Quintana ( 5 familias), Corrala Alegría (5 familias), Corrala la Ilusión (18 familias), Corrala la Esperanza (5 familias), Corrala la Libertad (7 familias), Corrala Liberación (25 familias), Corrala El Mirador (13 familias). Las corralas están impulsadas por la Intercomisión de Vivienda de la Asamblea 15M de Sevilla.

- PAH. La Plataforma de Afectados por la Hipoteca (ver ejemplo 3), desde su campaña Obra Social PAH (2011) propone el realojo de las familias desalojadas, en una campaña de ocupaciones y recuperación de viviendas vacías, reclamando el alquiler social para las familias, en función de su renta.

Las recuperaciones pueden ser individuales o colectivas. La campaña propone los procesos, metodologías y documentos para realizar las recuperaciones.

En esta campaña, se han realojado 1106 personas.

\subsection{Ejemplo 3. PAH. Plataforma de afectados por la hipoteca}

\begin{tabular}{|c|c|c|c|c|c|c|c|c|c|c|c|c|c|c|c|c|c|c|c|c|c|c|c|c|c|c|c|c|c|c|c|c|c|}
\hline \multicolumn{32}{|c|}{ Variables analizadas } & & \\
\hline \multicolumn{8}{|c|}{ Escala } & \multicolumn{6}{|c|}{ Factores que intervienen } & \multicolumn{5}{|c|}{$\begin{array}{l}\text { Agentes que inter- } \\
\text { vienen }\end{array}$} & \multicolumn{13}{|c|}{ Mecanismos que intervienen } & & \\
\hline \multirow{6}{*}{$\frac{\pi}{\frac{3}{0}}$} & \multirow[b]{3}{*}{ 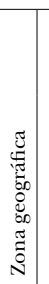 } & \multirow[b]{3}{*}{ हैं } & \multirow[b]{3}{*}{ 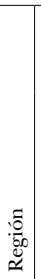 } & \multirow[b]{3}{*}{ 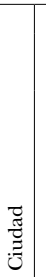 } & \multirow[b]{3}{*}{ 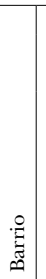 } & \multirow[b]{3}{*}{ 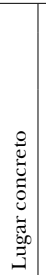 } & \multirow[b]{3}{*}{ 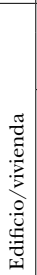 } & \multirow{2}{*}{\multicolumn{3}{|c|}{$\begin{array}{l}\text { Actividad } \\
\text { humana }\end{array}$}} & \multirow{2}{*}{\multicolumn{3}{|c|}{$\begin{array}{l}\text { Soporte fí- } \\
\text { sico }\end{array}$}} & \multirow[b]{3}{*}{$\mid$} & \multirow[b]{3}{*}{ 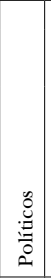 } & \multirow[b]{3}{*}{$\begin{array}{l}\stackrel{8}{\mathscr{B}} \\
\stackrel{\mathscr{U}}{\mathscr{U}} \\
\end{array}$} & \multirow[b]{3}{*}{ 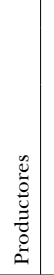 } & \multirow[b]{3}{*}{ : } & \multirow[b]{3}{*}{ 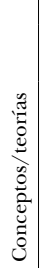 } & \multirow[b]{3}{*}{$\begin{array}{l}\stackrel{g}{g} \\
: \\
0\end{array}$} & \multirow[b]{3}{*}{ 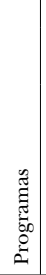 } & & \multirow{2}{*}{\multicolumn{9}{|c|}{$\begin{array}{l}\text { Técnicas } \\
\text { Sociales }\end{array}$}} & & \\
\hline & & & & & & & & & & & & & & & & & & & & & & \multirow[b]{2}{*}{ 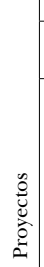 } & & & & & & & & & & & \\
\hline & & & & & & & & $\begin{array}{c} \\
\frac{\mathscr{b}}{\tilde{g}} \\
\dot{d} \\
\dot{n}\end{array}$ & 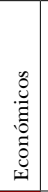 & $\frac{\stackrel{n}{\tilde{n}}}{\stackrel{n}{\Xi}}$ & 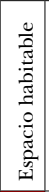 & 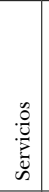 & 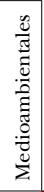 & & & & & & & & & & 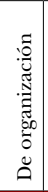 & 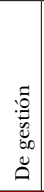 & 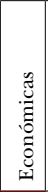 & 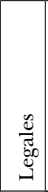 & 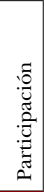 & 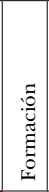 & 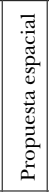 & 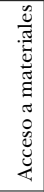 & 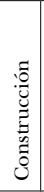 & & \\
\hline & & & & & & & & & & & & & & & & & & & & & & & & & & & & & & & & Autogestión & \\
\hline & & & & & & & & & & & & & & & & & & & & & & & & & & & & & & & & Cogestión & Para vivir \\
\hline & & & & & & & & & & & & & & & & & & & & & & & & & & & & & & & & Imposición & Para \\
\hline
\end{tabular}

Consecuencias directas de la crisis económica y, en especial, del llamado "pinchazo" de la burbuja inmobiliaria en España son:

- Las dificultades económicas para pagar los plazos establecidos en las hipotecas.

- La recuperación del valor real de las viviendas. Por un lado, el valor especulativo era mucho mayor y, por otro, se daban unas condiciones de embaucamiento, al facilitar hipotecas cercanas al o por el valor especulativo total, animando al usuario al endeudamiento (incluso con la financiación de muebles y otros bienes complementarios).
Cuadro 5. Ejemplo 3. PAH. Plataforma de Afectados por la Hipoteca. Fuente: Elaboración propia. 
El resultado es que, al no poder responder al pago del crédito, la deuda del usuario es mucho mayor que el valor actual del bien, lo que por un lado provoca el desahucio de los inquilinos y, además, la no aceptación de la devolución del bien como cancelación de la deuda (dación en pago).

La Plataforma de Afectados por la Hipoteca (PAH) nace de la propuesta de agrupación colectiva para evitar los desahucios. En este momento ha paralizado 1112 desahucios. El subtítulo de la plataforma es: "de la burbuja inmobiliaria al derecho a la vivienda". En todo su proceso ha aumentando objetivos y campañas:

- Dación en pago con carácter retroactivo.

- Mociones a los ayuntamientos, para influir en las políticas de vivienda, como son la recuperación de vivienda vacía o la regulación hipotecaria.

- Stop desahucios.

- Obra social PAH (Ver ejemplo 2) que promueve la reapropiación de las viviendas vacías.

- Escrache. Con el objetivo de romper la disciplina de voto de ciertos partidos contra los objetivos de la PAH.

El ejemplo, aparte de por su incidencia en los problemas reales del hábitat y por su nivel de eficacia, es significativo de la capacidad de autogestión y organización, a amplia escala, a partir de la solución de acciones concretas.

\subsection{Ejemplo 4. Gamonal, Burgos}

\begin{tabular}{|c|c|c|c|c|c|c|c|c|c|c|c|c|c|c|c|c|c|c|c|c|c|c|c|c|c|c|c|c|c|c|c|c|c|}
\hline \multicolumn{32}{|c|}{ Variables analizadas } & & \\
\hline \multicolumn{8}{|c|}{ Escala } & \multicolumn{6}{|c|}{ Factores que intervienen } & \multicolumn{5}{|c|}{$\begin{array}{l}\text { Agentes que inter- } \\
\text { vienen }\end{array}$} & \multicolumn{13}{|c|}{ Mecanismos que intervienen } & & \\
\hline \multirow{6}{*}{$\begin{array}{l}\frac{\pi}{0} \\
\frac{0}{0} \\
\text { U. }\end{array}$} & \multirow[b]{3}{*}{ 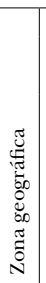 } & \multirow[b]{3}{*}{ 尝 } & \multirow[b]{3}{*}{ 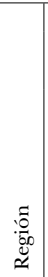 } & \multirow[b]{3}{*}{ 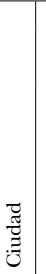 } & \multirow[b]{3}{*}{$\stackrel{\circ}{\stackrel{D}{\Xi}}$} & \multirow[b]{3}{*}{ 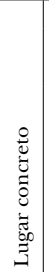 } & \multirow[b]{3}{*}{ 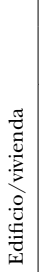 } & \multirow{2}{*}{\multicolumn{3}{|c|}{$\begin{array}{l}\text { Actividad } \\
\text { humana }\end{array}$}} & \multirow{2}{*}{\multicolumn{3}{|c|}{$\begin{array}{l}\text { Soporte fí- } \\
\text { sico }\end{array}$}} & \multirow[b]{3}{*}{ 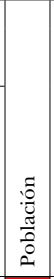 } & \multirow[b]{3}{*}{ 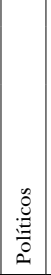 } & \multirow[b]{3}{*}{ 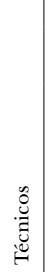 } & \multirow[b]{3}{*}{ 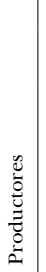 } & \multirow[b]{3}{*}{ 胥 } & \multirow[b]{3}{*}{ 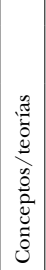 } & \multirow[b]{3}{*}{ : } & & & \multirow{2}{*}{\multicolumn{9}{|c|}{$\begin{array}{l}\text { Técnicas } \\
\text { Sociales }\end{array}$}} & & \\
\hline & & & & & & & & & & & & & & & & & & & & & \multirow[b]{2}{*}{ 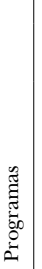 } & \multirow[b]{2}{*}{ 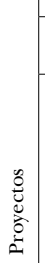 } & & & & & & & & & & & \\
\hline & & & & & & & & $\begin{array}{c} \\
0 \\
\frac{0}{\tilde{J}} \\
0 \\
0 \\
\infty\end{array}$ & 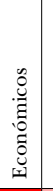 & 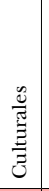 & 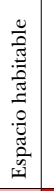 & 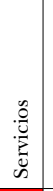 & 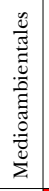 & & & & & & & & & & 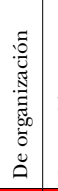 & 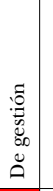 & 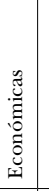 & 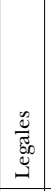 & 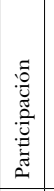 & 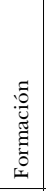 & 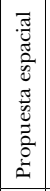 & 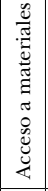 & 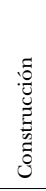 & & \\
\hline & & & & & & & & & & & & & & & & & & & & & & & & & & & & & & & & Autogestión & Parniriv \\
\hline & & & & & & & & & & & & & & & & & & & & & & & & & & & & & & & & Cogestión & Fara VIVIr \\
\hline & & & & & & & & & & & & & & & & & & & & & & & & & & & & & & & & Imposición & Para \\
\hline
\end{tabular}

Cuadro 6. Ejemplo 4. Gamonal, Burgos Fuente: Elaboración propia.
Las semanas del 6 al 18 de enero de 2014 son un ejemplo de la capacidad de organización y autogestión de la población de un barrio: Gamonal (60000 vecinos) de Burgos (180000 habitantes), en España, para defenderse de una imposición del alcalde de la ciudad.

La alcaldía había propuesto la transformación de la vía principal existente que atraviesa el barrio (Calle Vitoria de cuatro carriles de circulación actuales) por un bulevar de doble carril (uno en cada sentido), eliminando las plazas de aparcamiento de superficie y proponiendo un aparcamiento subterráneo de 246 plazas, con privatización del derecho al uso durante 40 años. Las obras suponían un elevado coste ( 8 millones de euros la calle y 5 millones el aparcamiento), en una situación actual de prioridad de otras necesidades barriales y de 18000 parados en el barrio. A esto se añade el agravante de que detrás de las propuestas de privatización está una empresa $(\mathrm{M} \& \mathrm{~B})$, cuyo propieta- 
rio (Méndez Pozo), fue condenado hace años en el famoso "juicio de la construcción" de la ciudad y que en la actualidad es, a su vez, dueño del diario de la ciudad y de la empresa que gestiona la TV pública de Castilla y León.

Ya las obras iniciadas (quitada la capa de rodadura asfáltica existente), los vecinos se organizan (había una plataforma "Bulevar ahora NO" que se había manifestado durante los últimos dos meses y que decide disolverse) e interrumpen las obras, bloqueando el paso de las máquinas y pidiendo la libertad de los arrestados en las manifestaciones de días anteriores.

El día 15 la protesta se extiende a Madrid y a otras zonas de España, con el lema "Todos somos Gamonal”. El sábado 18 se paralizan oficialmente las obras y se abandona el proyecto.

El caso Gamonal se convierte en un gran ejemplo de la capacidad de unión, organización y autogestión de los vecinos en defensa de un barrio para vivir, sin aceptar la imposición de un barrio para especular.

\subsection{Ejemplo 5. Marinaleda, Sevilla, España}

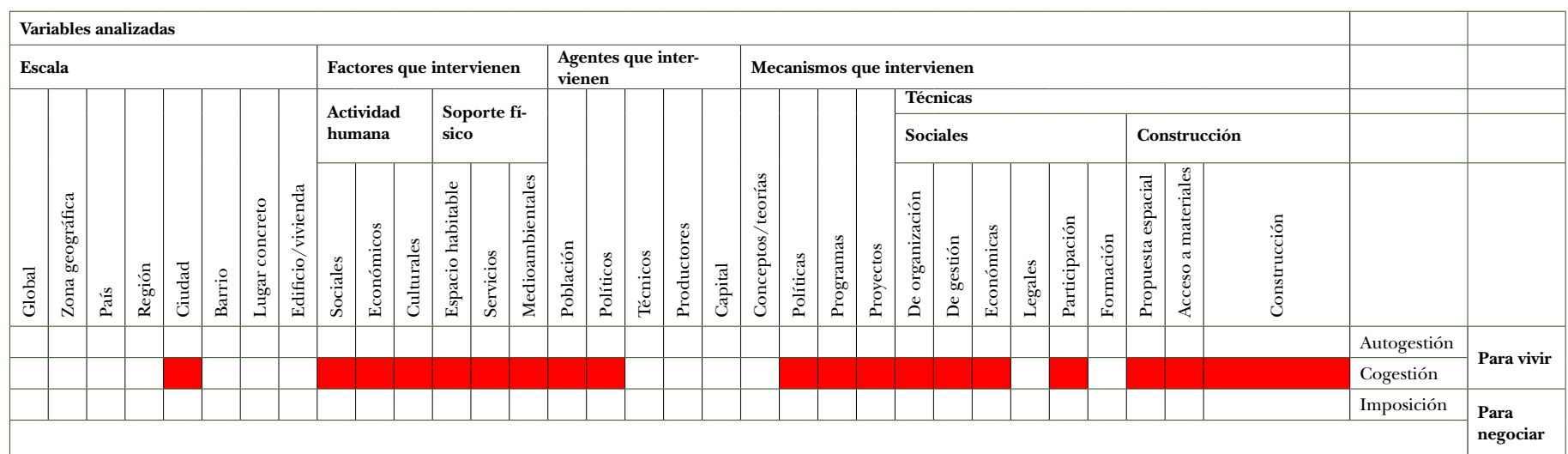

Buscar en España ejemplos de cogestión (gestión participativa en régimen de igualdad de los agentes que intervienen) es de una gran dificultad. Existen múltiples ejemplos de participación e incluso de logros de acuerdos conseguidos por los ciudadanos, pero siempre o muy mayoritariamente desde formas de organización propuestas por las administraciones (básicamente locales, a nivel de ciudad y barrio, o acción concreta) como son las mesas de participación, con carácter no vinculante, es decir, con predominio de los agentes políticos. En la mayoría de los casos son instrumentos para exhibir la participación, sin creer en ella, o para integrar no conflictivamente la opinión ciudadana, cuando no para justificar o ejercer el autoritarismo político y el de grupos defendidos por él, predominantemente promotores y comerciantes.

Un ejemplo singular en España es la organización y gestión del municipio de Marinaleda, de unos 2700 habitantes, situado a $100 \mathrm{~km}$ de Sevilla.

La gestión política tiene como referencia al alcalde Juan Manuel Sánchez Gordillo, del Colectivo de Unidad de los Trabajadores, Bloque Andaluz de Izquierdas (CUT) (Actúa dentro de Izquierda Unida, IU, de Andalucía) que ejerce el poder desde 1979 (inmediatamente después de la desaparición de la Dictadura en España, en plena Transición democrática).

El sistema aplicado y denominado democracia social, tiene como
Cuadro 7. Ejemplo 5. Marinaleda, Sevilla. Fuente: Elaboración propia. 
objetivo "el acceso a todos los bienestares sin límites, de la totalidad de los habitantes de nuestro pueblo".

La propuesta política es el reconocimiento de la necesidad de la participación directa en el pueblo, de la gente, de los ciudadanos, no el voto cada 4 años.

El sistema de organización consiste en:

- Asamblea general de todos los vecinos, que se reúne más de 20 veces al año y en la que participan, como promedio, más de 500 personas. Estas asambleas aprueban, por ejemplo, el presupuesto participativo.

- Asambleas de barrio, que se reúnen cuando hay temas concretos.

- Grupo de acción, que reúne a 25-30 personas, que componen los concejales, el comité ejecutivo del sindicato y los vecinos, por decisión personal o como representantes de grupos de actividad o asociaciones. Este grupo de acción se organiza en grupos de trabajo, abiertos.

- Un cuarto tipo de organización y participación son los Domingos Rojos, en los que se realizan trabajos comunitarios, no remunerados, como son los arreglos de calles, el cuidado de los jardines, la ayuda a la construcción de viviendas o al trabajo de las cooperativas agrícolas.

Aunque Marinaleda es un municipio eminentemente rural, en el que es prioritaria la producción agropecuaria como medio de vida, la mejora y/o producción del hábitat tiene una presencia muy importante en la gestión municipal. En este campo las propuestas son:

- Suelo. El objetivo es conseguir suelo. El método es la expropiación y municipalización de suelo que se cede gratuitamente a los autoconstructores.

- Vivienda. Para el fomento de la autoconstrucción se ceden materiales y asistencia técnica que facilita el proyecto técnico participativo y gratuito. Con este método se han construido unas 350 viviendas. Son de 3 habitaciones, baño y $100 \mathrm{~m}^{2}$ de patio. La vivienda es ampliable. El tiempo dedicado por el autoconstructor se descuenta del precio de la vivienda. Los autoconstructores, en asamblea, deciden el precio de la cuota mensual de ocupación de las viviendas (Referencia actual de cuota: 15 euros al mes).

En el área productiva, el pueblo tiene una almazara para producción de aceite, en los años ochenta lograron una expropiación (por parte de la Junta de Andalucía) de 1200 ha para la producción de los jornaleros, a partir de aquí se constituyó la cooperativa El Flumoso y en 1999 se abrió una fábrica de envasado de verduras.

En la cooperativa, que emplea al $50 \%$ de la población, todos tienen el mismo salario (1200 euros/mes/por 39,5 horas semanales) sean profesores o campesinos. Los políticos, alcalde y concejales no cobran por esos cargos y no existe policía municipal. 


\subsection{Ejemplo 6. Cooperativas de vivienda en España}

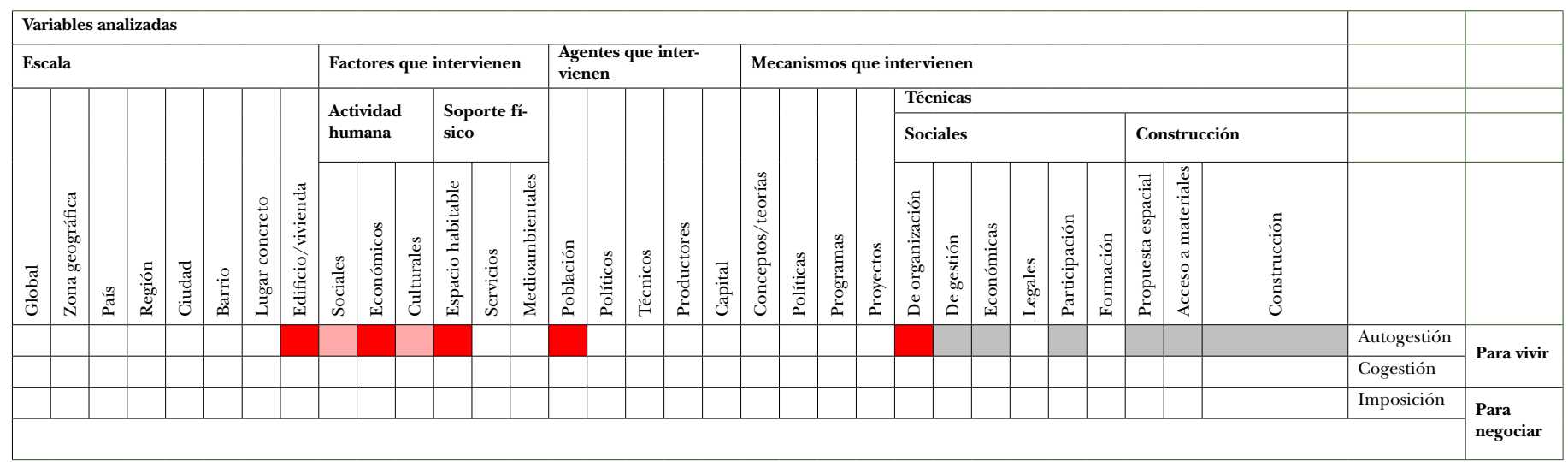

Las cooperativas de vivienda en España son organizaciones que, en el marco legal, producen socialmente vivienda. En general, las cooperativas son de diversos tipos (de producción y consumo principalmente), tienen una amplia presencia y son una solución de economía social alternativa en la actual crisis económica. Son un modelo de producción en auge como respuesta de los trabajadores al cierre de las empresas.

Desde 2008 se han fundado más de 100 empresas cooperativas al año, una cada 3 días, incluso empresas sin tradición cooperativa como son estudios de arquitectura, ingenierías o empresas de energías limpias. En zonas como el País Vasco (aunque ha sido un duro golpe el cierre reciente de la cooperativa FAGOR de producción de electrodomésticos) y Cataluña, tienen gran tradición. En Andalucía están surgiendo cooperativas de gestión y de trabajo asociado. Actualmente, según CEPES, Confederación Española de la Economía Social en España, hay más de 22000 cooperativas, más de la mitad de servicios, muchas dedicadas a vivienda y construcción. Ahora nacen las dedicadas a trabajo asociado, consumidores y usuarios, educación...

Sin embargo, las cooperativas de viviendas existentes (de propietarios) están sufriendo la presión de la crisis.

Tradicionalmente, de los tres principales factores básicos para la continuidad para las cooperativas de vivienda: cooperativistas, suelo y crédito, el problema era el suelo (cuando se tenía suelo se tenía crédito y cooperativistas interesados en el lugar). Ahora el problema es básicamente el crédito y el miedo económico de los cooperativistas (manteniéndose la necesidad), lo único que hay es suelo.

Están surgiendo iniciativas de cooperativas con distintos regímenes de tenencia: de alquiler (el estudio financiero las hace posibles), de propiedad colectiva y en especial de cesión de uso, conociéndose primeras experiencias en Cataluña (Sostrecivic, Can Batlló...) y propuestas en Andalucía.

Otra línea, en propuesta, son cooperativas con distintos tipos de tenencia, con una visión más amplia que la estricta vivienda, con servicios y mezcla de poblaciones que en este momento tienen grandes dificultades para acceder a la vivienda (jóvenes, jubilados, ancianos y familias jóvenes).
Cuadro 8. Ejemplo 6. Cooperativas de vivienda en España. Fuente: Elaboración propia. 


\subsection{Ejemplo 7. Ley de Costas. España}

\begin{tabular}{|c|c|c|c|c|c|c|c|c|c|c|c|c|c|c|c|c|c|c|c|c|c|c|c|c|c|c|c|c|c|c|c|c|c|}
\hline \multicolumn{32}{|c|}{ Variables analizadas } & & \\
\hline \multicolumn{8}{|c|}{ Escala } & \multicolumn{6}{|c|}{ Factores que intervienen } & \multicolumn{5}{|c|}{$\begin{array}{l}\text { Agentes que inter- } \\
\text { vienen }\end{array}$} & \multicolumn{13}{|c|}{ Mecanismos que intervienen } & & \\
\hline \multirow{6}{*}{$\frac{\pi}{\frac{\pi}{0}}$} & \multirow[b]{3}{*}{ 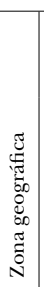 } & \multirow[b]{3}{*}{$\stackrel{\infty}{\pi}$} & \multirow[b]{3}{*}{$\mid$\begin{tabular}{l|}
$: 0$ \\
$: 0$ \\
$\check{0}$ \\
$\check{\simeq}$
\end{tabular}} & \multirow[b]{3}{*}{ 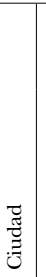 } & \multirow[b]{3}{*}{$\stackrel{\circ}{\stackrel{E}{E}}$} & \multirow[b]{3}{*}{ 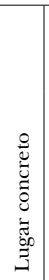 } & \multirow[b]{3}{*}{ 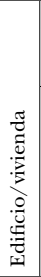 } & \multirow{2}{*}{\multicolumn{3}{|c|}{$\begin{array}{l}\text { Actividad } \\
\text { humana }\end{array}$}} & \multirow{2}{*}{\multicolumn{3}{|c|}{$\begin{array}{l}\text { Soporte fí- } \\
\text { sico }\end{array}$}} & \multirow[b]{3}{*}{$\mid$} & \multirow[b]{3}{*}{ 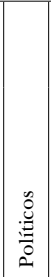 } & \multirow[b]{3}{*}{ 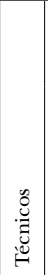 } & \multirow[b]{3}{*}{ 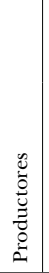 } & \multirow[b]{3}{*}{ 胥 } & \multirow[b]{3}{*}{ 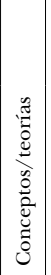 } & \multirow[b]{3}{*}{ 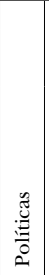 } & & \multirow[b]{3}{*}{ 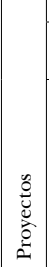 } & \multirow{2}{*}{\multicolumn{9}{|c|}{\begin{tabular}{|l|} 
Técnicas \\
Sociales
\end{tabular}}} & & \\
\hline & & & & & & & & & & & & & & & & & & & & & \multirow[b]{2}{*}{ 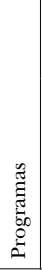 } & & & & & & & & & & & & \\
\hline & & & & & & & & 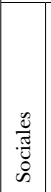 & 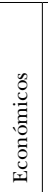 & 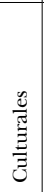 & 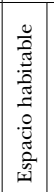 & 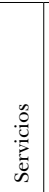 & 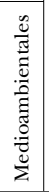 & & & & & & & & & & 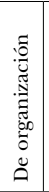 & 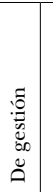 & 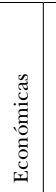 & 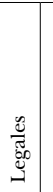 & 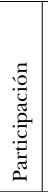 & 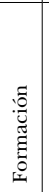 & 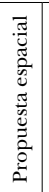 & 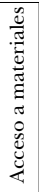 & 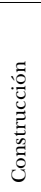 & & \\
\hline & & & & & & & & & & & & & & & & & & & & & & & & & & & & & & & & Autogestión & Para vivir \\
\hline & & & & & & & & & & & & & & & & & & & & & & & & & & & & & & & & Cogestión & Para vivir \\
\hline & & & & & & & & & & & & & & & & & & & & & & & & & & & & & & & & Imposición & Para \\
\hline
\end{tabular}

Cuadro 9. Ejemplo 7. Ley de Costas. España. Fuente: Elaboración propia.
El 29 de mayo de 2013 se aprobó en España la nueva Ley de Costas (de irónico nombre: Ley de Protección y Uso Sostenible del Litoral), al amparo de la mayoría absoluta del partido en el poder (PP). La anterior Ley de Costas se promovió en España en 1988, para controlar el impacto producido en las costas por el gran incremento de la edificación especulativa, con el objetivo de ofrecer espacio turístico (en proceso de gran crecimiento), lo que suponía el control de la construcción de apartamentos, hoteles y viviendas de segunda residencia (vivienda complementaria a la residencia principal) en un momento de optimismo del Estado de Bienestar. A este objetivo, se sumó recientemente la consciencia de los riesgos derivados del cambio climático, de la situación de riesgo de las poblaciones asentadas en zonas muy cercanas al borde del mar y, por lo tanto, de las edificaciones donde se alojan.

La propuesta de la nueva ley supone una amnistía y consolidación de construcciones mal situadas de acuerdo con la antigua ley, como son grandes hoteles cuya construcción estaba paralizada y ahora se podrán acabar, salva a más de 10000 viviendas construidas en zonas anteriormente no permitidas, en muchos casos en zonas de riesgo, por lo que estaba prevista su destrucción en el 2018, y da una moratoria de otros 75 años a unos 100 hoteles a mas de 200 industrias y a unos 100 restaurantes y bares.

La nueva ley actúa principalmente con dos propuestas:

1. Reconsidera el límite del dominio público del borde del mar, proponiendo una nueva medición del mismo que acredite la franja de invasión de mar en los últimos 50 años. Este límite puede avanzar hacia el mar si no se acredita esta invasión del mar.

Esto puede suponer, por ejemplo, la desprotección de zonas de dunas, permitiendo urbanizaciones como la propuesta en Valdecaballeros (Tarifa).

2. La servidumbre de protección de la costa, situada en la zona de dominio privado, con prohibición de la construcción permanente y limitación del resto de edificaciones (públicas, no permanentes, etc.) se reduce, en determinadas condiciones, de 100 $\mathrm{m}$ a $20 \mathrm{~m}$. Se considera que más de 100000 viviendas y múltiples hoteles, algunos paralizados en su construcción, están en esta zona. La nueva ley permitirá acabar los hoteles y edificaciones y reparar y consolidar las viviendas que estaban en precario en zonas de riesgo. 
Es importante comprobar (es una constante en las propuestas unilaterales políticas) la contradicción entre el nombre de la ley (Ley de Protección y Uso Sostenible del Litoral) y los verdaderos objetivos (estos sí políticos) de defensa de los intereses particulares y en especial del capital, en contra de los intereses sociales, económicos y culturales, generales.

La nueva ley es un gran ejemplo de la gestión autoritaria bajo el paraguas de la democracia representativa.

\section{Influencia de la escala de actuación}

En la figura 6 se refleja la relación de los tres tipos de gestión: imposición, cogestión y autogestión, con las distintas escalas de intervención, a partir de los 7 ejemplos escogidos y de dos referencias de acciones globales: derecho a la vivienda y derecho a la ciudad.

Cuando se analiza el dominio de las escalas de intervención, se observa:

\subsection{Grandes escalas}

El poder político y el poder económico dominan las grandes escalas, imponiendo sus criterios e intereses. Fundamentalmente dominan los Estados y, a través de ellos, las ciudades, barrios y lugares concretos.

El ciudadano, a través de la democracia representativa, tiene muy limitada la posibilidad de reequilibrio, o de aceptación de sus iniciativas, para la mejora o defensa de su hábitat.

El poder político y económico estatal, prioritariamente muy fuertemente asociados, solo ven limitada su acción impositiva cuando reciben directrices desde dos posibles ámbitos:

- Desde las decisiones globales y de las áreas internacionales a las que pertenecen, por ejemplo, derechos aceptados (como es el derecho a la vivienda) o directrices de la Unión Europea.

- Desde las acciones concretas y a pequeña escala que demuestran las situaciones insostenibles provocadas por las imposiciones y la necesidad de superarlas. Un ejemplo sería la Plataforma de Afectados por la Hipoteca (PAH).

La influencia de estas dos escalas, global y pequeña escala, en la decisiva escala estatal, en la regional y en las ciudades (administración local) es lenta, aunque en situaciones de crisis como la presente en España pueden provocar conmociones o transformaciones importantes, incluso de cambio de modelo o predominio económico, y sobre todo de modelo político, de transición de una democracia representativa a una democracia participativa, redistribuidora.

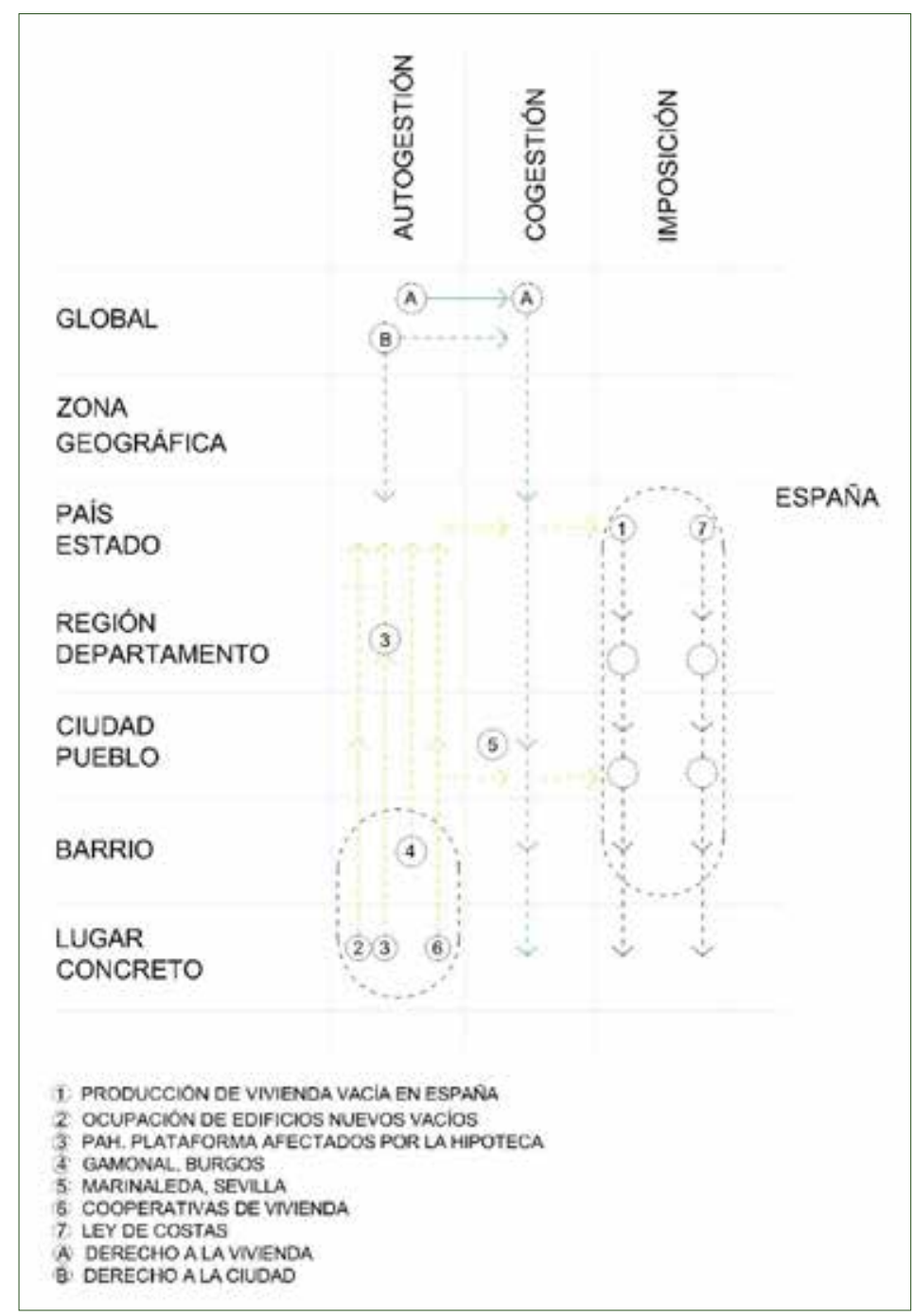

Figura 8: Relación: escala de intervención-tipos de gestión. Fuente: Elaboración propia. 


\subsection{Pequeñas escalas}

\subsubsection{Autogestión}

La actuación a pequeña escala es muy eficaz y esto por varios motivos:

- Cuando la realidad depende de la propia decisión (autogestión) individual o colectiva, el resultado es directamente favorable para la solución de las necesidades y posibilidades habitacionales.

- Cuando la autogestión se extiende a mayores escalas, edificios de vivienda en régimen de cooperativas o movimientos barriales, el predominio de la propuesta de ciudad para vivir frente a la ciudad para negociar es evidente. El edificio, el espacio habitable y la vida que en él se desarrolla, así como el barrio o la ciudad, se resienten positivamente.

Las actuaciones a pequeña escala son ejemplares para las grandes escalas, los mecanismos aplicados a menudo son asumidos en otros lugares y escalas por políticos (que se sienten representantes de los electores y no de otros intereses) y técnicos (que aprenden quiénes son sus verdaderos clientes) dando lugar, incluso, a cambio de normativas, legislación y políticas.

Un ejemplo sería el reconocimiento de la eficacia de la participación, incipiente y sesgada en España, hasta el momento no vinculante (su gran limitación), pero evolutiva y generadora de acuerdos y metodologías que permiten ver la posibilidad de aceptación de la cogestión (igualdad frente a la decisión), eficaz en casos concretos.

Una condición básica para lograr los objetivos de transformación a gran escala, desde las pequeñas escalas, es realizar acciones concretas, replicables y ejemplares que hagan que otra realidad sea posible.

\subsubsection{Cogestión}

Encontrar ejemplos de cogestión en España ha sido casi imposible. El ejemplo de Marinaleda (ejemplo 5) es único, pero significativo.

Es significativo que se realice en un municipio entero, a partir de una propuesta política consciente y bastante personal, que con los años (desde 1979) se convierte en un medio de convivencia, en un ecosistema. Las iniciativas de agentes generales en presencia serán aislarle, desmitificarle, criticarle, sublimar las contradicciones, pero hay una manera sencilla y fresca (ecológica y sostenible) de observarle y admirarle en su eficacia, en su sencillez, humildad y lógica social.

Otros ejemplos de cogestión, incipientes, pueden encontrarse en la mejora habitacional y barrial. Se podría identificar una evolución de la visión política de la participación, hacia una aceptación de su propia modernización ante la fuerza de los nuevos movimientos sociales.

\section{Conclusión}

Para la mejora y/o producción del hábitat es absolutamente necesario trabajar desde el propio lugar social, económico, cultural y territorial, a la propia escala de decisión, pero conectado con las múltiples experiencias que se hacen en otros lugares y con la voluntad de incidir y transformar a todas las escalas posibles. 
No a todas las escalas se actúa o se puede actuar de igual forma.

Lograr acciones concretas a la propia escala permite incidir y transformar las decisiones políticas a gran escala. 


\section{Referencias bibliográficas generales}

\section{Generales}

AAVV (1997). ¿Sostenible? Barcelona: UPC. Icaria Editorial.

Gallopin, G. (2003). Sostenibilidad y desarrollo sostenible: Un enfoque sistémico. Santiago de Chile: Naciones Unidas, CEPAL.

Montaner, J. M. y Muxí, Z. (2011). Arquitectura y política. Barcelona: GG.

Ortiz, E. y Zárate, M. L. (2002). Vivitos y Coleando. México: UAM.

Pelli, V. (2006). Habitar, participar, pertenecer. Buenos Aires: Nobako.

Salas, J.; Oteiza, I. y Colavidas, F. (2006). Hacia una manualística universal de habitabilidad básica. Madrid: Mairea Libros.

Schelotto, S., et. al. (2013). (Des)Bordes Urbanos. Politica. Proyecto y Gestión Sostenible en la ciudad de la periferia. Montevideo: Monografías.

Sepúlveda, R. y Fernández Wagner, R. (2006). Un análisis crítico de las politicas nacionales de vivienda en América Latina. San José: Centro cooperativo Sueco.

\section{ESPECÍfICAS DE LOS EJEMPLOS}

Ejemplo 1. Producción de vivienda básica en España.

Alliaranguren, J. C. Urbanismo y vivienda. La interacción de las politicas de suelo y vivienda. Conferencia en el Tercer Congreso Español de Derecho Urbanístico, Pamplona 25 de mayo de 2005.

Burbuja inmobiliaria en España. Recuperado el 1 de junio de 2014, de: http//es.wikipedia.org/wiki/burbuja_inmobiliaria_en_españa\%C3\%B1a

Díaz Hernández, R.; Parreño Castellano, J. M. (2006). La política económica, la construcción de vivienda y la producción de la ciudad en España (1939-75). Scripta Nova. Revista electrónica de geografía y ciencias sociales, X, 218. Recuperado el 1 de junio de 2014, de: http://www.ub.edu/geocrit/sn/sn-218-48.htm

Naredo, J. M. (2010). El modelo Inmobiliario Español y sus consecuencias. Boletín $C F+S>44$. Tierra y Libertad. Recuperado el 1 de junio de 2014, de: http:/ / habitat. aq.upm.es/boletin/n44/ajnar.html

Pellicer, L. y Galindo, C. Urbanizaciones fantasma (1). Más de seiscientos mil pisos nuevos sin vender. $E l$ País, 24/11/2013.
Pellicer, L. Urbanizaciones fantasmas (2). Bloques vacíos junto al Ebro. El País, 25/11/2013.

Reinero, D. Urbanizaciones fantasmas (3). Nadie compra un piso en Barreiros. El País, 26/11/2013.

Rodríguez, R. (2004). Infrautilización del parque de viviendas en España: aparición de viviendas vacías y secundarias. Boletín $C F+S>$ Notas para entender el mercado inmobiliario. Recuperado el 1 de junio de 2014, de: http://habitat.aq.upm.es/boletin/n29/arrod3. html

Vinuesa, J. (2008). La vivienda vacía en España: Un despilfarro social y territorial insostenible. Scripta Nova. Revista electrónica de geografía y ciencias sociales, XII, 270. Recuperado el 1 de junio de 2014, de: http://www.ub.edu/geocrit/-xcol/74.htm

Ejemplo 2. Ocupación de edificios nuevos vacios.

Propuesta de plan de trabajo en materia de vivienda en Sevilla, para el periodo noviembre 2012-septiembre 2013. $15 \mathrm{M}$ Sevilla.

Ejemplo 3. PAH. Plataforma de Afectados por la Hipoteca.

Colau, A. y Alemany, A. (2013). 2007-2012. Retrospectiva de desahucios y ejecuciones hipotecarias en España, estadisticas oficiales e indicadores. PAH.

Iniciativa Legislativa Popular. Proposición de Ley de Regulación de Dación en Pago, de Paralización de los Desahucios y de Alquiler Social (Propuesta de la PAH).

Ejemplo 4. Gamonal, Burgos.

Gómez, M. Los disturbios vuelven a la "zona cero" por tercer día. El País, 13/01/2014.

La presión vecinal paraliza la polémica obra de Burgos. El País, 14/01/2014.

$\mathrm{El}$ alcalde de Burgos paraliza definitivamente las obras de Gamonal. El País, 18/01/2014.

Gómez, L. Una milla de oro para Gamonal que nadie pidió. El País, 14/01/2014.

Ejemplo 7. Ley de Costas.

Ciento cuarenta mil casas podrían acogerse a la amnistía de obras de la Ley de Costas. El País, 26/10/2013.

Ecologistas en Acción (2007). Informe infracciones Ley de Costas.

El gobierno da luz ver a la nueva ley de costas que indulta a miles de viviendas. El País, 05/10/2012.

Más chiringuitos, menos playa. El País, 02/03/2014. Viudez, J. Y este desmán quedó amnistiado. El País, 20/02/2013. 
GÁLLIGO, Pedro Lorenzo. Influencia de la ESCALA de decisión e intervención en el proceso de mejora y producción social del hábitat. (La gestión y el control social de la ciudad). Hábitat y Sociedad, 2015, n. ${ }^{\circ}$ 8, pp. 43-72.

$<$ www.habitatysociedad.us.es>

http://dx.doi.org/10.12795/HabitatySociedad.2015.i8.03

$\bigcirc$ 